\title{
Effects of using certain tree species in forest regeneration on regional wind damage risks in Finnish boreal forests under different CMIP5 projections
}

\author{
V.-P. Ikonen ${ }^{1}$ (D) - A. Kilpeläinen ${ }^{1} \cdot$ H. Strandman ${ }^{1} \cdot$ A. Asikainen ${ }^{2} \cdot$ A. Venäläinen ${ }^{3} \cdot$ H. Peltola ${ }^{1}$ (D)
}

Received: 16 October 2017 / Revised: 9 March 2020 / Accepted: 18 March 2020 / Published online: 8 April 2020

(c) The Author(s) 2020

\begin{abstract}
We studied how the use of certain tree species in forest regeneration affected the regional wind damage risks to Finnish boreal forests under the current climate (1981-2010) and recent-generation global climate model (GCM) predictions (i.e., 10 GCMs of CMIP5, with wide variations in temperature and precipitation), using the representative concentration pathways RCP4.5 and RCP8.5 over the period 2010-2099. The study employed forest ecosystem and mechanistic wind damage risk model simulations on upland national forest inventory plots throughout Finland. The amount of wind damage was estimated based on the predicted critical wind speeds for uprooting trees and their probabilities. In a baseline management regime, forest regeneration was performed by planting the same tree species that was dominant before the final cut. In other management regimes, either Scots pine, Norway spruce or silver birch was planted on medium-fertility sites. Other management actions were performed as for a baseline management. The calculated amount of wind damage was greatest in southern and central Finland under CNRM-CM5 RCP8.5, and the smallest under HadGEM2-ES RCP8.5. The most severe climate projections (HadGEM2-ES RCP8.5 and GFDL-CM3 RCP8.5) affected the wind damage risk even more than did the tree species preferences in forest regeneration. The situation was the opposite for the less severe climate projections (e.g., MPI-ESM-MR RCP4.5 and MPI-ESM-MR RCP8.5). The calculated amount of wind damage was clearly greater in the south than in the north, due to differences in forest structure. The volume of growing stock is much higher in the south for the more vulnerable Norway spruce (and birch) than in the north, which is opposite for the less vulnerable Scots pine. The increasing risk of wind damage should be taken into account in forest management because it could amplify, or even cancel out, any expected increases in forest productivity due to climate change.
\end{abstract}

Keywords Climate change $\cdot$ Forest management $\cdot$ Gap-type forest ecosystem model $\cdot$ Mechanistic wind damage model $\cdot$ RCP4.5 $\cdot$ RCP8.5 $\cdot$ Tree species preference $\cdot$ Wind damage

\section{Introduction}

Since the 1990s, strong winds and storms have caused large economic losses to forestry in central and northern Europe

Communicated by Arne Nothdurft.

V.-P. Ikonen

veli-pekka.ikonen@uef.fi

1 Faculty of Science and Forestry, School of Forest Sciences, University of Eastern Finland, P.O. Box 111, 80101 Joensuu, Finland

2 Natural Resources Institute Finland, P.O. Box 68, 80101 Joensuu, Finland

3 Finnish Meteorological Institute, P.O. Box 503, 00101 Helsinki, Finland
(Schelhaas et al. 2003; Gardiner et al. 2010; Schuck and Schelhaas 2013). In northern Europe, and in forested countries like Finland, most wind damage has occurred in stands adjacent to newly clear-cut areas, or in recently heavily thinned older stands (Laiho 1987; Zubizarreta-Gerendiain et al. 2012; Suvanto et al. 2016). During the coming decades, the risk of wind damage to forests is expected to increase, although the frequency and severity of the storms may not increase (Nikulin et al. 2011; Pryor et al. 2012; Outten and Esau 2013; Mölter et al. 2016). This is due to the reduced period of frozen soil and tree anchorage in winter (Peltola 
et al. 1999a; Kellomäki et al. 2010; Gregow et al. 2011a; Lehtonen et al. 2018). The soil is expected to barely freeze at all, for example, in southern and central Finland by 2100 under severe climate warming.

In Finland, about $45 \%$ of the volume of growing stock is currently accounted for by Scots pine (Pinus sylvestris L.), $31 \%$ by Norway spruce [Picea abies (L.) Karst.] and $24 \%$ by silver and downy birch (Betula pendula Roth and Betula pubescens Ehrh.) and other broadleaves (Finnish Forest Research Institute 2014). The increased cultivation of Norway spruce and its proportion of the growing stock volume may greatly increase the risk of wind damage to forests in Finland because Norway spruce, with its shallow rooting system, is more vulnerable to uprooting (i.e., lower critical wind speeds would be needed) than Scots pine and birch (Peltola et al. 1999b, 2010). Also, in central Europe, Norway spruce has already suffered the most wind damage among the conifers (Schmidt et al. 2010; Reyer et al. 2017).

Climate change is expected to increase the productivity of forests, especially in the northern boreal zone, due to improving growing conditions (Bergh et al. 2003; BriceñoElizondo et al. 2006; Koca et al. 2006; Kellomäki et al. 2008, 2018; Poudel et al. 2011). At the same time, it may decrease the productivity in the southern boreal zone (Koca et al. 2006; Kellomäki et al. 2008, 2018; Reyer et al. 2017). The responses of forests to climate change may differ greatly at the regional level. This is related to differences in the prevailing environmental conditions (climate, site), current forest structure (age, species) and forest management regimes (Bergh et al. 2003; Briceño-Elizondo et al. 2006; Garcia-Gonzalo et al. 2007; Kellomäki et al. 2008; Lindner et al. 2010; Alrahahleh et al. 2018). Particularly under severe climate warming, the growth and success of Norway spruce are expected to decrease in Finland, especially on southern upland forest sites, if the growing conditions (temperature and water availability) become suboptimal for its growth (Briceño-Elizondo et al. 2006; Jyske et al. 2010; Kellomäki et al. 2018; Ruosteenoja et al. 2018). Increasing forest disturbances, such as wind damage, may also amplify, or even cancel out, any expected increases in the productivity of forests under changing climate (Kellomäki et al. 2008; Reyer et al. 2017).

According to Ikonen et al. (2017), the increased cultivation of Norway spruce under changing climate will increase the wind damage risk and the amount of damage in Finland, in the long run. Furthermore, tree species preference in forest regeneration may affect the wind damage risk more than the climate change, based on recent-generation global climate model (GCM) predictions (i.e., multi-model means of the Coupled Model Intercomparison Project Phase 5-CMIP5), using the representative concentration pathways RCP4.5 and RCP8.5 over the period 2010-2099 (Ruosteenoja et al. 2016). Based on these multi-model means for RCP4.5 and RCP8.5, mean temperature and precipitation are expected to increase in Finland, depending on geographical region, by an average of $3-5{ }^{\circ} \mathrm{C}$ and $7-14 \%$, respectively, during April-September by 2070-2099. Concurrently, atmospheric $\mathrm{CO}_{2}$ concentrations are expected to increase from the current value of 360 to $536 \mathrm{ppm}$ (RCP4.5) and $807 \mathrm{ppm}$ (RCP8.5) during the period 2070-2099.

Apart from the multi-model means for RCP4.5 and RCP8.5, certain individual GCMs, such as GFDL-CM3 RCP8.5 and HadGEM2-ES RCP8.5, have predicted up to a $6-7{ }^{\circ} \mathrm{C}$ increase in temperature during the potential growing season by 2070-2099, depending on geographical region in Finland. At the same time, they predict a slight to moderate increase in precipitation in the north, but only a slight increase (GFDL-CM3 RCP8.5), or a decrease (HadGEM2ES RCP8.5), in precipitation in the south. Under such severe climate change outlooks, an increased cultivation of Norway spruce may decrease the growth and volume of growing stock, especially under southern boreal conditions, more than predicted, based on the multi-model means of the GCMs (Alrahahleh et al. 2018). Consequently, the severe climate projections (HadGEM2-ES RCP8.5 and GFDL-CM3 RCP8.5) may affect the wind damage risk even more than the tree species preferences in forest regeneration, which should be considered in forest management decision making.

Depending on the severity of the climate change projection, radically different adaptive measures for forestry might be useful. For example, Norway spruce could grow well on certain sites under less severe climate projections and thus would be preferred in forest regeneration, but this would not be the case for more severe climate projections (Alrahahleh et al. 2018). Therefore, the use of different individual GCM projections under RCPs is required in considering the uncertainties in the model predictions for forest growth and dynamics and consequently for the wind damage risks to forests. This is needed in order to properly adapt forest management to climate change. The forest ecosystem models, together with up-to-date information on current forest resources, and different climate projections offer a means of predicting forest growth and dynamics under changing management regimes and environmental conditions, respectively (Garcia-Gonzalo et al. 2007; Seidl and Lexer 2013; Alrahahleh et al. 2017, 2018; Reyer et al. 2017). The use of the simulated outputs of forest ecosystem models as inputs for mechanistic wind damage models also offers a means of predicting the threshold wind speeds needed for wind damage to forests and, consequently, their probabilities and the 
amount of damage to expect (Gardiner et al. 2008; Peltola et al. 2010; Seidl et al. 2014; Ikonen et al. 2017).

In this context, we studied how the use of certain tree species in forest regeneration could affect the regional wind damage risks to Finnish boreal forests under the current climate (1981-2010) and recent-generation global climate model (GCM) predictions (i.e., 10 GCMs of CMIP5, with wide variations in temperature and precipitation; Ruosteenoja et al. 2016), using RCP4.5 and RCP8.5 over the period 2010-2099. The study employed forest ecosystem (SIMA; Kellomäki et al. 2005, 2008, 2018) and mechanistic wind damage (HWIND; Peltola et al. 1999b) model simulations on upland National Forest Inventory (NFI) plots throughout Finland. In a baseline management regime, forest regeneration was performed by planting the same tree species that was dominant before the final cut. In other management regimes, either Scots pine, Norway spruce or silver birch was planted on medium-fertility sites. Other management actions concerning rotation were performed as for baseline management.

We hypothesized that the use of certain individual GCM runs of CMIP5 could lead to contradictory results for the expected wind damage risks to those predicted based on the multi-model means under RCP4.5 and RCP 8.5 by Ikonen et al. (2017). In addition, we expected that very severe climate change projections could affect the wind damage risk to a greater degree than tree species preferences in forest regeneration. The same simulation layout was recently used by Alrahahleh et al. (2018), who studied how the use of certain tree species in forest regeneration affected the volume growth, timber yield and carbon stock of boreal forests in Finland under different CMIP5 projections.

\section{Material and methods}

\section{Initial stand and site data}

The initial stand and site characteristics used in the simulations were based on the 10th National Forest Inventory of Finland (see Korhonen 2016 for more details). One randomly selected sample plot from every permanent cluster of sample plots on upland forest land assigned to timber production throughout Finland was used (see Table 1 for more details). Altogether, the data included 2642 sample plots, of which most-1388 plots-were on medium-fertile mesic sites (Myrtillus type, MT), 529 were on fertile herbrich (Oxalis myrtillus type) or more fertile sites, 641 were on less fertile subxeric sites (Vaccinium type), and 84 were on poorer, dryish sites (Cladonia type).

\section{Climate data}

The climate data for the current climate were based on measurements made by the Finnish Meteorological Institute (FMI) of temperature and precipitation over the period 1981-2010. For the climate change projections, we used the results from 10 individual GCMs (four GCMs driven by both RCP4.5 and RCP8.5 and two additional GCMs driven by RCP8.5 only), which were downloaded from the CMIP5 database by the FMI (Fig. 1, Table 2; Ruosteenoja et al. 2016). These individual GCMs give very different climate projections, even under the same radiative forcing scenario (e.g., RCP8.5). The reasons for this may be many, such as the GCMs being produced by different research institutes (and countries of origin) differing in terms of model parameterization and structure, using different input datasets, spatial resolution and numerical algorithms (see Ruosteenoja et al. 2016). For comparison, in this study, we used the multimodel mean values of 28 individual GCMs under RCP4.5 and RCP8.5, which are the same as those used in a study by Ikonen et al. (2017).

The 10 selected GCMs, which have a proven ability to relatively accurately simulate the temperature and precipitation of the current climate (1981-2010) in northern Europe (Lehtonen et al. 2016a, 2016b; Ruosteenoja et al. 2016), provided us with a good representation of the overall variability in the full ensemble of CMIP5 projections for monthly mean temperatures and precipitation for 2010-2099. Too high or low predicted values for daily mean temperatures and precipitation, in relation to the observed data, however, still needed to be bias-corrected, which was done using an empirical bias correction method called quantile mapping (see for more details, Räisänen and Räty 2013; Räty et al. 2014). Both the observational and climate change data were interpolated by the FMI onto a $10 \times 10 \mathrm{~km}$ grid throughout Finland, using the kriging with external drift method (see for more details, Venäläinen et al. 2005; Aalto et al. 2013, 2016), before they were used in the simulations.

\section{Management activities}

In our forest ecosystem model simulations under a baseline management regime, forest regeneration was always done by planting the same tree species that was dominant before the final cut. In other management regimes, either Scots pine, Norway spruce or silver birch were planted on mediumfertility (MT) sites, as all these tree species are suitable for such sites. On other site types, baseline management was followed. Other management actions concerning rotation were performed as for the baseline management (Table 1). 
Table 1 Simulation layout with stand and site conditions, climate projections and management activities (same simulation layout was used also in the study of Alrahahleh et al. 2018)

\begin{tabular}{|c|c|}
\hline Simulation layout & Description \\
\hline Initial stand and site conditions & $\begin{array}{l}\text { The initial stand and site characteristics represented one randomly selected sample plot of } \\
\text { NFI10 from every permanent cluster of sample plots on upland forest land assigned to } \\
\text { timber production. Southern Finland denoted for the area of old administrational Forest } \\
\text { Centre units } 1-6 \text {, central Finland units } 7-10 \text { and northern Finland units } 11-13 \text {, respectively. } \\
\text { The average distance between the clusters of sample plots is } 6 \times 6 \mathrm{~km} \text { in units } 1-12 \text { and } \\
10 \times 10 \mathrm{~km} \text { in unit } 13 \text {. Each sample plot had on average of nine trees, for which tree species } \\
\text { and diameter at breast height }(\mathrm{dbh}, \mathrm{cm}) \text { were available }\end{array}$ \\
\hline Climate data & $\begin{array}{l}\text { Current climate data (1981-2010), four GCMs driven by both RCP4.5 and RCP } 8.5 \text { and two } \\
\text { additional GCMs driven by RCP } 8.5 \text { only, and multi-model mean values driven by both } \\
\text { RCP4.5 and RCP } 8.5 \text { forcing scenarios (2010-2099) }\end{array}$ \\
\hline Species-specific response to the temperature sum & $\begin{array}{l}\text { Minimum }\left(\mathrm{TS}_{\min }, 370,390,390 \text { degree days, d.d.), maximum }\left(\mathrm{TS}_{\max }, 2060,2500,4330 \text { d.d.) }\right.\right. \\
\text { and optimum }\left(\mathrm{TS}_{\mathrm{opt}}, 1215,1445,2360 \text { d.d.) temperature sum values for growth were small- }\right. \\
\text { est in Norway spruce, followed by Scots pine and birch }\end{array}$ \\
\hline Soil moisture availability & $\begin{array}{l}\text { The field capacity and wilting point defined the soil moisture available for tree growth on dif- } \\
\text { ferent site and soil types as affected by precipitation and evaporation. Scots pine was more } \\
\text { drought tolerant than other tree species }\end{array}$ \\
\hline $\begin{array}{l}\text { Initial amount of soil organic matter (and car- } \\
\text { bon) and nitrogen }\end{array}$ & $\begin{array}{l}\text { The initial amounts of soil organic matter (and carbon) and nitrogen available for growth were } \\
\text { defined based on the site fertility type and regional temperature sum of the current climate. } \\
\text { Atmospheric nitrogen deposition of } 10 \mathrm{~kg}_{\text {year }}^{-1} \text { was assumed (Järvinen and Vänni1994; } \\
\text { Kellomäki et al. 2005) }\end{array}$ \\
\hline Forest regeneration & $\begin{array}{l}\text { In a baseline management, it was planted the same tree species that was dominant before the } \\
\text { final cut. In alternative regimes, either Scots pine, Norway spruce or silver birch was planted } \\
\text { on medium-fertile (MT) sites. In planting it was used } 2000 \text { seedlings ha }{ }^{-1} \text { for Norway } \\
\text { spruce and Scots pine, and } 1600 \text { seedlings ha }{ }^{-1} \text { for silver birch (diameter of } 2.5 \mathrm{~cm} \text { ). In } \\
\text { addition, seedlings were expected to regenerate naturally at all sites }\end{array}$ \\
\hline Tending of seedling stand & $\begin{array}{l}\text { Tending of the seedling stand was done before the first commercial thinning by removing } \\
\text { mostly smaller or suppressed trees }\end{array}$ \\
\hline Thinnings and final felling & $\begin{array}{l}\text { The region-, site- and tree species-specific management recommendations were used as a } \\
\text { basis for the timing and intensity of thinnings (from below), and timing of final felling. } \\
\text { When the basal area threshold for thinning was reached, at a given dominant height, the } \\
\text { thinning could be done by reducing the basal area to the recommended threshold value after } \\
\text { thinning. Final felling was performed based on the basal area weighted diameter at breast } \\
\text { height (with a range } 22-30 \mathrm{~cm} \text { depending on region, site and tree species). However, on } \\
\text { average, a 13-year delay in harvesting was used, compared to the management recommenda- } \\
\text { tions }\end{array}$ \\
\hline Harvesting intensity & $\begin{array}{l}\text { Only timber (sawlogs and pulpwood with minimum top diameters of } 15 \mathrm{~cm} \text { and } 6 \mathrm{~cm} \text { ) was } \\
\text { harvested, and logging residues were left at the site }\end{array}$ \\
\hline Other information & $\begin{array}{l}\text { Parts of plots from central }(10 \%) \text { to northern }(30 \%) \text { Finland were left outside management, } \\
\text { unlike in southern Finland, where the current forest conservation area is very small, at } \\
\text { around } 2 \% \text { (Finnish Forest Research Institute 2014) }\end{array}$ \\
\hline
\end{tabular}

As a basis for the tending of seedling stands, thinnings and final fellings, region-, site- and tree species-specific management rules were used (Äijälä et al. 2014). On the other hand, on average, a 13-year delay in thinnings and final fellings was used, compared to the management recommendations, because these are often delayed in practice (see Finnish Forest Research Institute 2014). Parts of the forest plots from central to northern Finland were also left outside of management, unlike in southern Finland, where currently the total forest conservation area is very small (Finnish Forest Research Institute 2014). This has been done previously by
Ikonen et al. (2017) and Alrahahleh et al. (2018), resulting in more realistic predictions for the growth and volume of growing stock for the first 30-year simulation period (2010-2039) under current climate, compared to the forest statistics for the period 2004-2009 (Finnish Forest Research Institute 2014).

\section{Outlines for the forest ecosystem model}

A gap-type forest ecosystem model SIMA (Kellomäki et al. $2005,2008,2018$ ) was used to simulate the regeneration, 

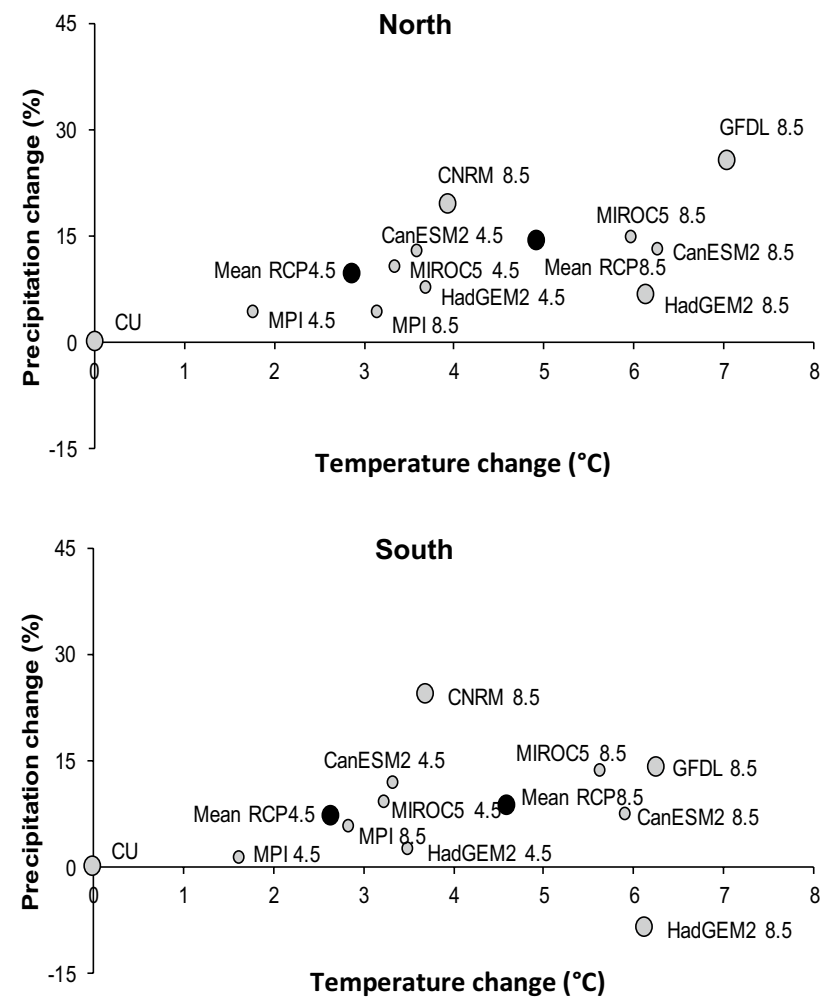

Fig. 1 Climate change projections with temperature and precipitation change in April-September in the third period, 2070-2099, in northern, central and southern Finland (average of the 30-year period). Black circles represent the climate change projections 'Mean RCP4.5' and 'Mean RCP8.5' (means of 28 individual model runs),
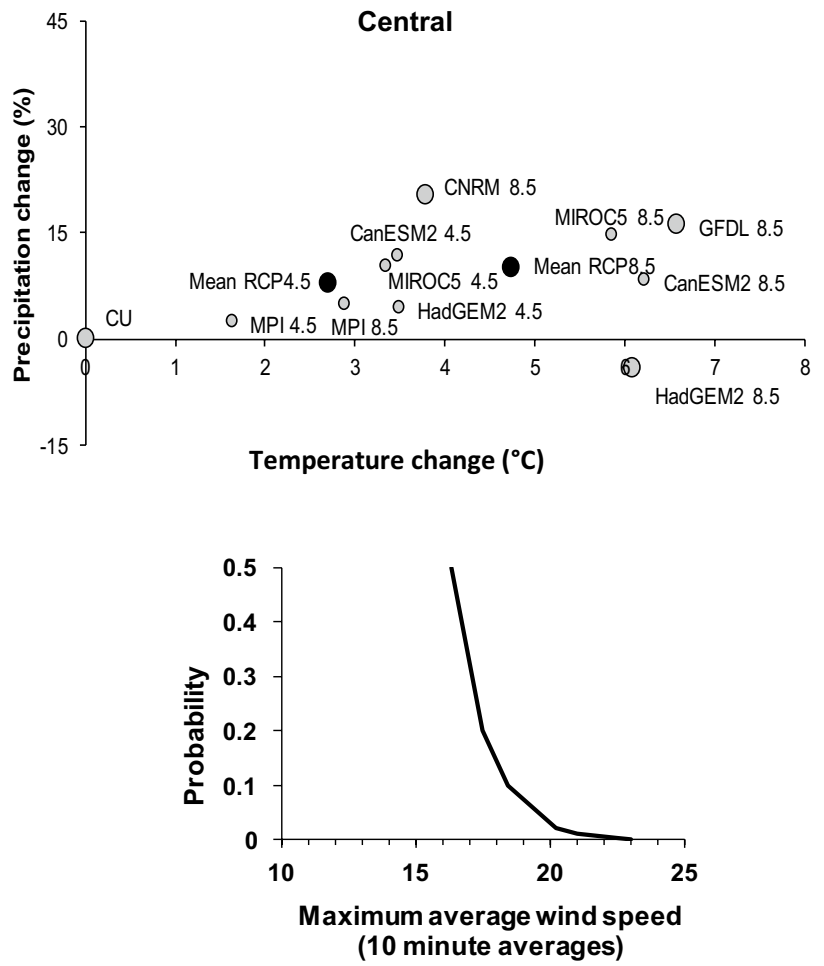

and gray circles represent individual climate change projections and the current climate. The changes are relative to the baseline climate (1981-2010). Also, the probabilities of $10 \mathrm{~min}$ (measured) maximum average wind speeds in Helsinki-Vantaa Airport weather station are presented (based on Peltola et al. 2010)
Table 2 Mean changes in temperature $\left(\Delta T,{ }^{\circ} \mathrm{C}\right)$ and precipitation $(\Delta P, \%)$ under different CMIP5 projections (i.e., multi-model means and individual GCMs) during potential growing seasons (April-September) in the period 2070-2099 in southern (old administrational
Forest Centre Units 1-6) and northern (11-13) Finland, in comparison to current climate (1981-2010, with a mean atmospheric $\mathrm{CO}_{2}$ concentration of $360 \mathrm{ppm})$

\begin{tabular}{|c|c|c|c|c|c|}
\hline \multirow{2}{*}{$\begin{array}{l}\text { Climate model acronym } \\
\text { (short name in bold) }\end{array}$} & \multirow[t]{2}{*}{ Institution/country of origin } & \multicolumn{2}{|c|}{$\Delta T\left({ }^{\circ} \mathrm{C}\right)$} & \multicolumn{2}{|c|}{$\Delta P(\%)$} \\
\hline & & South & North & South & North \\
\hline HadGEM2-ES RCP4.5 & Met Office Hadley Centre for Climate Science and Services, UK & 3.5 & 3.7 & 2 & 8 \\
\hline HadGEM2-ES RCP8.5 & & 6.1 & 6.1 & -9 & 7 \\
\hline MPI-ESM-MR RCP4.5 & Max Planck Institute for Meteorology, Germany & 1.6 & 1.8 & 1 & 4 \\
\hline MPI-ESM-MR RCP8.5 & & 2.8 & 3.1 & 6 & 4 \\
\hline CanESM2 RCP4.5 & Canadian Centre for Climate Modelling and Analysis, Canada & 3.3 & 3.6 & 12 & 13 \\
\hline CanESM2 RCP8.5 & & 5.9 & 6.3 & 7 & 13 \\
\hline MIROC5 RCP4.5 & Atmosphere and Ocean Research Institute (University of Tokyo), & 3.2 & 3.3 & 9 & 11 \\
\hline MIROC5 RCP8.5 & $\begin{array}{l}\text { National Institute for Environmental Studies and Japan Agency for } \\
\text { Marine-Earth Science and Technology, Japan }\end{array}$ & 5.6 & 6 & 13 & 15 \\
\hline CNRM-CM5 RCP8.5 & National Center for Meteorological Research, France & 3.7 & 3.9 & 24 & 19 \\
\hline GFDL-CM3 RCP8.5 & NOAA Geophysical Fluid Dynamics Laboratory, USA & 6.3 & 7 & 14 & 26 \\
\hline Mean (28) GCMs, RCP4.5 & - & 2.6 & 2.9 & 7 & 10 \\
\hline Mean (28) GCMs, RCP8.5 & - & 4.6 & 4.9 & 9 & 14 \\
\hline
\end{tabular}

The predicted mean atmospheric $\mathrm{CO}_{2}$ concentrations under the RCP4.5 and RCP8.5 forcing scenarios were $536 \mathrm{ppm}$ and 807 ppm, respectively, for the period 2070-2099. Other information for individual GCMs available in Ruosteenoja et al. (2016) 
growth and mortality of trees in boreal upland forests (on mineral soils) throughout Finland. Under optimal conditions, the growth and/or regeneration are not assumed to be limited by temperature sum $\left(\mathrm{TS}>5{ }^{\circ} \mathrm{C}\right.$ threshold), light availability, soil moisture or nitrogen supply. In addition, growth is affected by atmospheric $\mathrm{CO}_{2}$ concentration, atmospheric nitrogen deposition and tree maturity (diameter at $1.3 \mathrm{~m}$ above the ground). The tree diameter is further used to calculate tree height and the mass of tree organs (foliage, branches, stem and roots).

The species-specific response to the temperature sum was modeled for the main Finnish boreal tree species, based on a downward-opening symmetrical parabola (Kienast 1987; Nikolov and Helmisaari 1992; Kellomäki et al. 2008, 2018). This was done by assuming that the minimum and maximum values of the temperature sum define the geographical distribution of each tree species throughout the boreal zone (Table 1). In calculating the effects of changing climate on forest growth, only the changes in monthly temperature sums from April to September (i.e., the potential growing season), compared with the temperature sum of the current climate, were taken account (Torssonen et al 2015; Kellomäki et al. 2018). This was done in order to consider the prevailing light conditions.

Field capacity and wilting point define the soil moisture available for tree growth at different sites and soil types, as affected by precipitation and evaporation. Under optimum conditions, soil moisture is greater than the wilting point (no dry days). The initial amount of soil organic matter (and carbon) and nitrogen available for growth are defined based on the site fertility type and the regional temperature sum of the current climate (see Kellomäki et al. 2005, 2008). The amount of soil organic matter (and carbon) and nitrogen available for growth are also affected by the input of litter and deadwood to the soil layer, and their decay.

In our simulations, management included control over artificial regeneration (planting) with the desired spacing and tree species (including naturally born seedlings), over stand density in tending the seedling stand, and over thinning and the final cut (only timber was harvested in this study; Table 1). The initial properties of a tree stand were described in terms of tree species, including the number of trees per hectare in each diameter class. The model simulations were carried out with a time step of one year on an area of $100 \mathrm{~m}^{2}$, based on the Monte Carlo technique (see, e.g., Bugmann et al. 1996), based on which certain events, such as the birth and death of trees, are stochastic events. Therefore, only the mean tendency of several iterations was considered in further data analyses (e.g., 20 iterations in this study, for which a coefficient of variation for the volume of growing stock was $1.6 \%$ over a 90 -year simulation period at the plot level, based on our calculations).

Previous results from model simulations have shown good agreement (a correlation of 0.857 ) with the measured average annual volume growth (1996-2003) of the main Finnish boreal tree species on the permanent upland National Forest Inventory plots for different regions of Finland (Kellomäki et al. 2008). Routa et al. (2011) also showed that the simulated mean annual volume growth of Norway spruce and Scots pine stands, on medium-fertility sites in 13 different locations throughout Finland, using the SIMA model and a statistical growth and yield model (MOTTI; Hynynen et al. 2002) indicated a good agreement between the SIMA and MOTTI simulations $\left(R^{2}=0.85\right)$.

\section{Outlines for a mechanistic wind damage model}

In this work, the outputs of the SIMA model for different sample plots (i.e., tree species, tree height and diameter at breast height (DBH) for each sample tree and stand density) were used as inputs for a mechanistic wind damage model (HWIND; Peltola et al. 1999b), which predicts the critical wind speeds (CWSs, $\mathrm{m} \mathrm{s}^{-1}$ ) needed to uproot Scots pine, Norway spruce and birch trees in various stand configurations. The CWSs are computed at a height of $10 \mathrm{~m}$ above an open lawn surface (10 min averages; see Dupont et al. 2015). A tree is uprooted if its maximum bending moment exceeds the resistance of the root-soil plate, and breaks if it exceeds the resistance of the stem (Peltola et al. 1999b). In calculating the CWS for individual trees in a stand, the stand density and dominant stand height are used to calculate the mean wind profile, which is later applied to individual trees.

Based on previous HWIND simulations (see, e.g., Peltola et al. 1999b; Dupont et al. 2015), Norway spruce, with the shallowest rooting, has the lowest CWS, followed by birch (in leaf, in summer), and Scots pine (with the deepest rooting) with the highest CWS, using the same tree and stand characteristics. In autumn, without leaves, birch is supposed to have a very low/no risk because of its low surface area (i.e., very high CWS needed). The outputs of the HWIND model (i.e., the CWSs needed to uproot or break trees at the stand edge) have been in reasonable 
agreement with other mechanistic wind damage models, such as GALES and FOREOLE (see Gardiner et al. 2000; Ancelin et al. 2004).

The properties of the HWIND model, its parameters, inputs and the validity of its outputs, as well as its performance for upland forests in Finland and Sweden, have been discussed in detail by, for example, Peltola et al. (1999b), Blennow and Sallnäs (2004), Zeng et al. (2006) and Gardiner et al. (2008). HWIND has also identified reasonably well the observed wind-damaged areas in previous case studies in Finland and Sweden (Talkkari et al. 2000; Blennow and Sallnäs 2004; Zubizarreta-Gerendiain et al. 2012).

In this study, the CWS calculations were performed by assuming unfrozen soil conditions and only considering the uprooting of trees. This was done because forests are vulnerable to wind damage in Finland mainly in unfrozen soil, and uprooting is the most common wind damage type. Under frozen soil conditions, stem breakage, which was not considered here, is the typical failure type (Peltola et al. 2000). It was also assumed that all trees at risk were located within one dominant stand height distance from the new upwind stand edge, where they have been observed to have the greatest risk of damage under Finnish conditions (Peltola et al. 1999b; Zubizarreta-Gerendiain et al. 2012). Thus, our CWS values represent the maximum vulnerability of trees to uprooting.

\section{Critical wind speeds, their probabilities and amount of wind damage}

Based on the calculated CWSs and their probabilities, we estimated the amount of wind damage using the approach outlined by Ikonen et al. (2017). First, we calculated the average minimum CWS for each sample plot (over all tree species in one simulation run), over each 30 -year period (2010-2039, 2040-2069 and 2070-2099). The average minimum CWSs were also calculated separately, assuming either birch in leaf (summer) or leafless (autumn). Leafless birch has a very low surface area for wind to affect, so has a very low risk of wind damage. Trees with a height of $<10 \mathrm{~m}$ were also considered to have very low/no risk. Under Finnish conditions, forest stands are not liable to wind damage before the first commercial thinning (see, e.g., ZubizarretaGerendiain et al. 2012), which is done at a dominant height of about 12-16 m (see Äijälä et al. 2014).

The annual probabilities (dimensionless, in a range of $0-1$ ) of the average minimum CWS were calculated throughout Finland using the probabilities of 10-min maximum average wind speeds, estimated by weather station at Helsinki Airport, i.e.,
$P_{\mathrm{cws}}=e^{y} /\left(1+e^{y}\right)$

where

$y=21.79-1.058 \times \mathrm{CWS}$

Peltola et al. (2010) and Zubizarreta-Gerendiain et al. (2017) (Fig. 1). This was done because the probabilities of strong wind speeds have been observed to be, on average, highest in southernmost Finland, followed by northern Finland (Peltola et al. 2010). Helsinki Airport data could also be considered to be highly representative for typical wind damage conditions in Finland, such as at the immediate downwind edges of new forest clear-cuts. Also, based on a preliminary analysis using different GCMs under different RCPs (FMI, unpublished results), this situation may not change in Finland, and wind conditions may not differ greatly under unfrozen or frozen soil conditions.

Based on the probabilities for the CWSs and the average volume of growing stock, we then estimated the volume of growing stock at risk $\left(\mathrm{m}^{3} \mathrm{ha}^{-1}\right)$, and the amount of damage $\left(\mathrm{m}^{3} \mathrm{ha}^{-1} \mathrm{a}^{-1}\right)$ and percentage of damage to the volume of growing stock. In calculating the volume of growing stock at risk, and the amount of damage, we assumed that all sample trees were located within one stand height distance from the new vulnerable upwind edge, and that only a small proportion $(3 \%)$ of the total stem volume would be damaged, based on the study by Zubizarreta-Gerendiain et al. (2012).

The results calculated at the plot level were then averaged for southern, central and northern Finland, over each 30-year period, for the current and all changing climate projections, under baseline management and increased use of different tree species in forest regeneration. The ranges of the results are shown for the different GCMs in order to demonstrate the sensitivity of the predictions to them. In addition, the results for current climate, the multi-model mean projections (mean RCP 4.5 and mean RCP 8.5), and the most extreme GCM projections (CNRM 8.5, HadGEM2 8.5 and GFDL 8.5) are discussed in more details below.

\section{Results}

\section{Calculated average minimum CWSs and their probabilities}

In the first 30-year period under the current climate, with baseline management, the predicted average minimum CWSs were smaller in summer (birch in leaf). They were also smaller in southern Finland $\left(16 \mathrm{~m} \mathrm{~s}^{-1}\right)$ than in central 

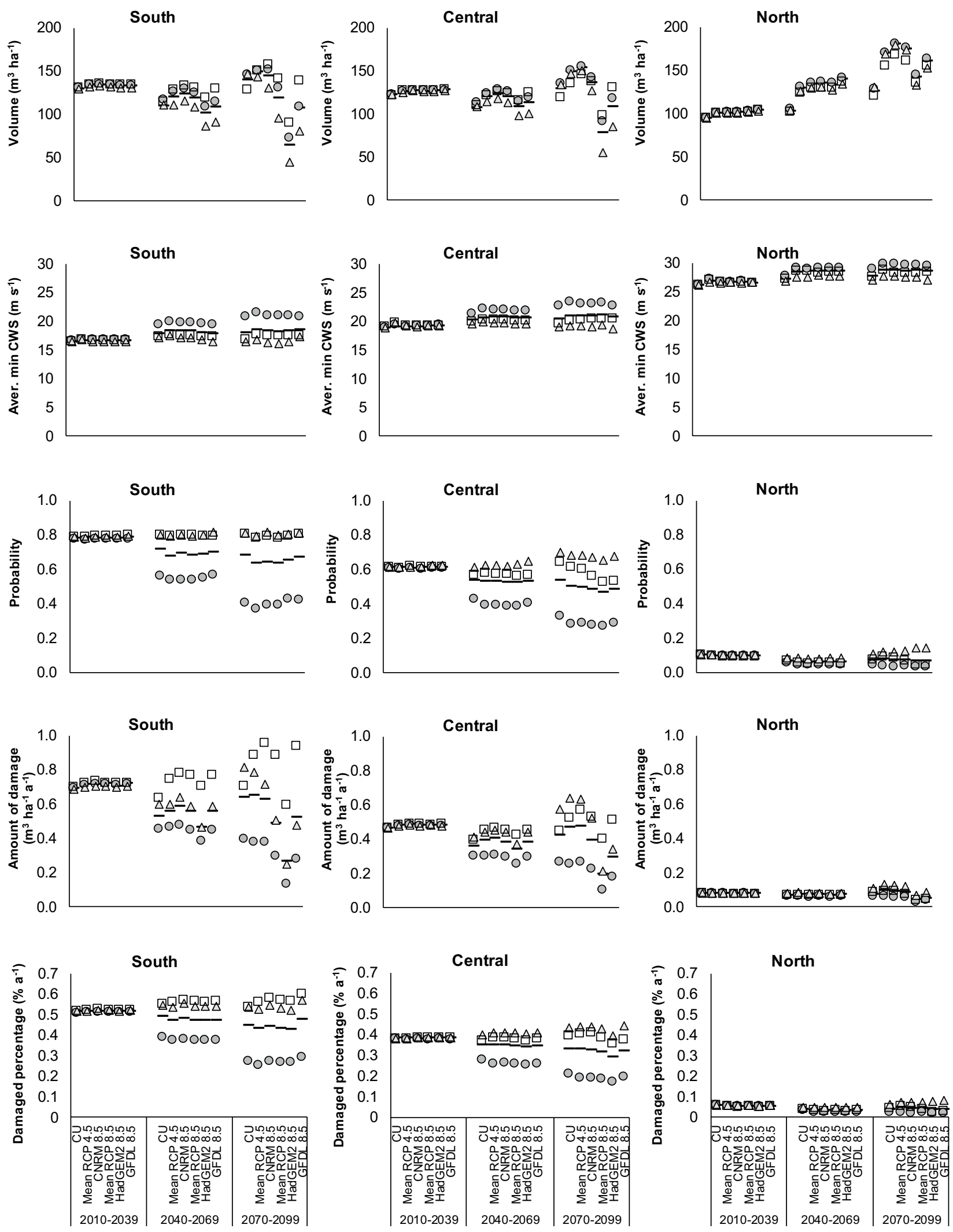

-Baseline OPref. SP $\triangle$ Pref. NS $\square$ Pref. Birch 
4Fig. 2 Average volume of growing stock $\left(\mathrm{m}^{3} \mathrm{ha}^{-1}\right)$, average minimum CWS $\left(\mathrm{m} \mathrm{s}^{-1}\right)$, predicted probabilities (dimensionless, in a range of 0-1) based on average minimum CWSs, amount of damage $\left(\mathrm{m}^{3} \mathrm{ha}^{-1} \mathrm{a}^{-1}\right)$ and damaged percentage $\left(\% \mathrm{a}^{-1}\right)$ in summer for each period and each management scenario under several climate change projections in southern, central and northern Finland. Medium-fertility sites were planted with Scots pine (Pref. SP), Norway spruce (Pref. NS) or silver birch (Pref. B), or with the tree species that was dominant before the final clear-felling (baseline management)

$\left(19 \mathrm{~m} \mathrm{~s}^{-1}\right)$ and northern $\left(27 \mathrm{~m} \mathrm{~s}^{-1}\right)$ Finland (Figs. 2, 3, Appendix Table 3). Also, under the $10 \mathrm{GCM}$ projections in the third 30-year period, they were smallest in southern Finland. They were the smallest with an increased use of Norway spruce $\left(16-17 \mathrm{~m} \mathrm{~s}^{-1}\right.$ ), followed by an increased use of birch (17-18 $\left.\mathrm{m} \mathrm{s}^{-1}\right)$, baseline management $\left(18-19 \mathrm{~m} \mathrm{~s}^{-1}\right)$, and an increased use of Scots pine $\left(20-21 \mathrm{~m} \mathrm{~s}^{-1}\right)$. In central and northern Finland, the tendency of the CWS ranges was similar to that in southern Finland, but with ranges of $18-23 \mathrm{~m} \mathrm{~s}^{-1}$ and $27-30 \mathrm{~m} \mathrm{~s}^{-1}$, respectively.

Under the current climate, with baseline management, the probability of wind damage in the summer was the highest in southern (0.8), followed by central (0.6) and northern (0.1) Finland, in the first 30-year period (Fig. 2, Appendix Table 4). In the third 30-year period, the probability of wind damage was in the range of $0.4-0.8,0.3-0.7$ and $0.0-0.1$ in southern, central and northern Finland, respectively, under the 10 GCM projections. The probabilities were the lowest with an increased use of Scots pine, and the highest with an increased use of both Norway spruce and birch, and having marginal differences between each GCM projection. Generally, CWSs were higher in autumn (leafless birch) than in summer, regardless of management regime or climate projection (Figs. 3, 4).

\section{Calculated amount of wind damage}

Under the current climate, with baseline management, the calculated average amount of wind damage in summer was highest in southern $\left(0.7 \mathrm{~m}^{3} \mathrm{ha}^{-1} \mathrm{a}^{-1}\right)$, followed by central $\left(0.5 \mathrm{~m}^{3} \mathrm{ha}^{-1} \mathrm{a}^{-1}\right)$ and northern $\left(0.1 \mathrm{~m}^{3} \mathrm{ha}^{-1} \mathrm{a}^{-1}\right)$ Finland, in the first 30-year period (Figs. 2, 5, Appendix Table 5). In the third 30-year period, under 10 GCM projections, the calculated average amount of wind damage was in the range of $0.3-0.7 \mathrm{~m}^{3} \mathrm{ha}^{-1} \mathrm{a}^{-1}$ in southern Finland, when baseline management scenario was applied. With an increased use of Scots pine, the corresponding range was $0.1-0.4 \mathrm{~m}^{3} \mathrm{ha}^{-1} \mathrm{a}^{-1}$ (the smallest), whereas with an increased use of Norway spruce, it was $0.2-0.8 \mathrm{~m}^{3} \mathrm{ha}^{-1} \mathrm{a}^{-1}$, and with an increased use of birch, it was $0.6-1.0 \mathrm{~m}^{3} \mathrm{ha}^{-1} \mathrm{a}^{-1}$ (the largest). In central Finland, the calculated amount of damage was in the range of $0.1-0.7 \mathrm{~m}^{3} \mathrm{ha}^{-1} \mathrm{a}^{-1}$. There, in general, it was the smallest with an increased use of Scots pine and the greatest with an increased use of Norway spruce and birch. In northern Finland, the calculated amount of damage was marginal.

In general, both the increased use of a certain tree species and the intensity of climate change affected the amount of damage. In southern and central Finland, the calculated amount of damage was the greatest under CNRM 8.5 (similar to mean RCP 4.5) and the smallest under HadGEM2 8.5 ; however, the most extreme climate change projections (HadGEM2 8.5 and GFDL 8.5) affected the amount of wind damage risk even more than did tree species preference in forest regeneration, opposite to the mild climate change scenario (such as MPI 4.5 and MPI 8.5).

Under the current climate, with baseline management, the damage percentage (relative share of damage to the average volume of growing stock) in summer was greatest in southern $(0.5 \%)$, followed by central $(0.4 \%)$ and northern (0.1\%) Finland, in the first 30-year period (Fig. 2). In the third 30-year period, under $10 \mathrm{GCM}$ projections, the corresponding range was $0.3-0.6 \%$ in southern and $0.2-0.4 \%$ in central Finland, whereas it was marginal in northern Finland. The damage percentages were the lowest with an increased use of Scots pine, and the highest with an increased use of Norway spruce and birch. In general, individual GCM projections affected the damage percentages much less than the preference for different tree species in forest regeneration.

\section{Discussion and conclusions}

\section{Evaluation of study approaches}

In this study, we used several climate change projections, with wide variations in temperatures and precipitation, in simulations by forest ecosystem (SIMA) and mechanistic wind damage (HWIND) models, in order to study the changes to regional risks of wind damage in Finnish upland boreal forests under different tree species preferences in forest regeneration over the period 2010-2099. Following the approach of Ikonen et al. (2017), we calculated the annual probability for wind damage and the amount of wind damage, for NFI plots throughout Finland, based on the predicted CWSs. Compared to our study, recent studies on climate change impacts on forests have mainly considered either the effects of climate change on productivity or on disturbances (Reyer et al. 2017). This is, although disturbances may affect forest productivity, e.g., via a decrease in 


\section{Summer}

(Birch in leaf)

Baseline manag.

2070-2099

Baseline manag.

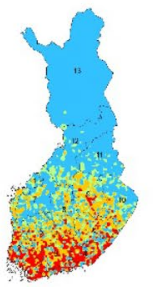

Current climate
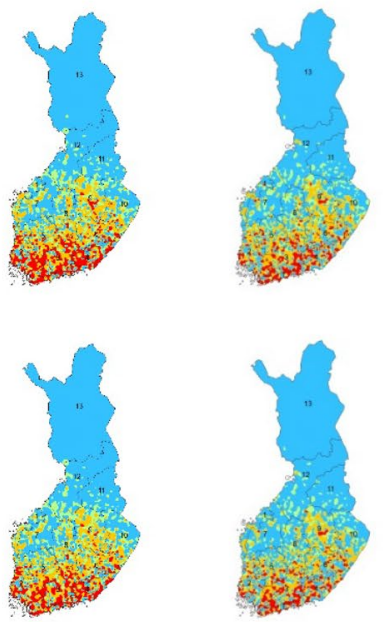

CNRM 8.5

HadGEM2 8.5
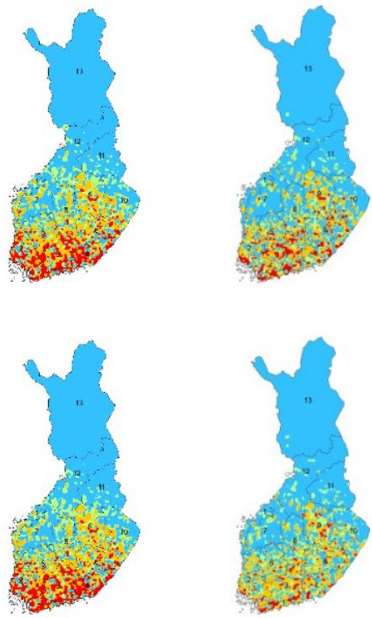

GFDL 8.5
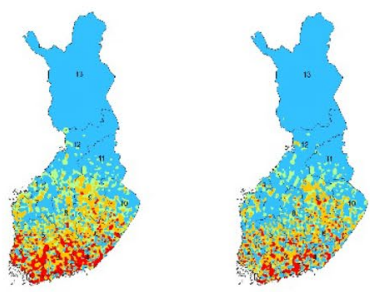

Mean RCP4.5

Mean RCP8.5

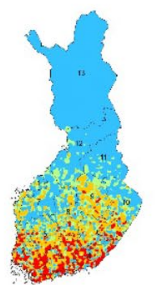

2010-2039

2070-2099

Pref. SP
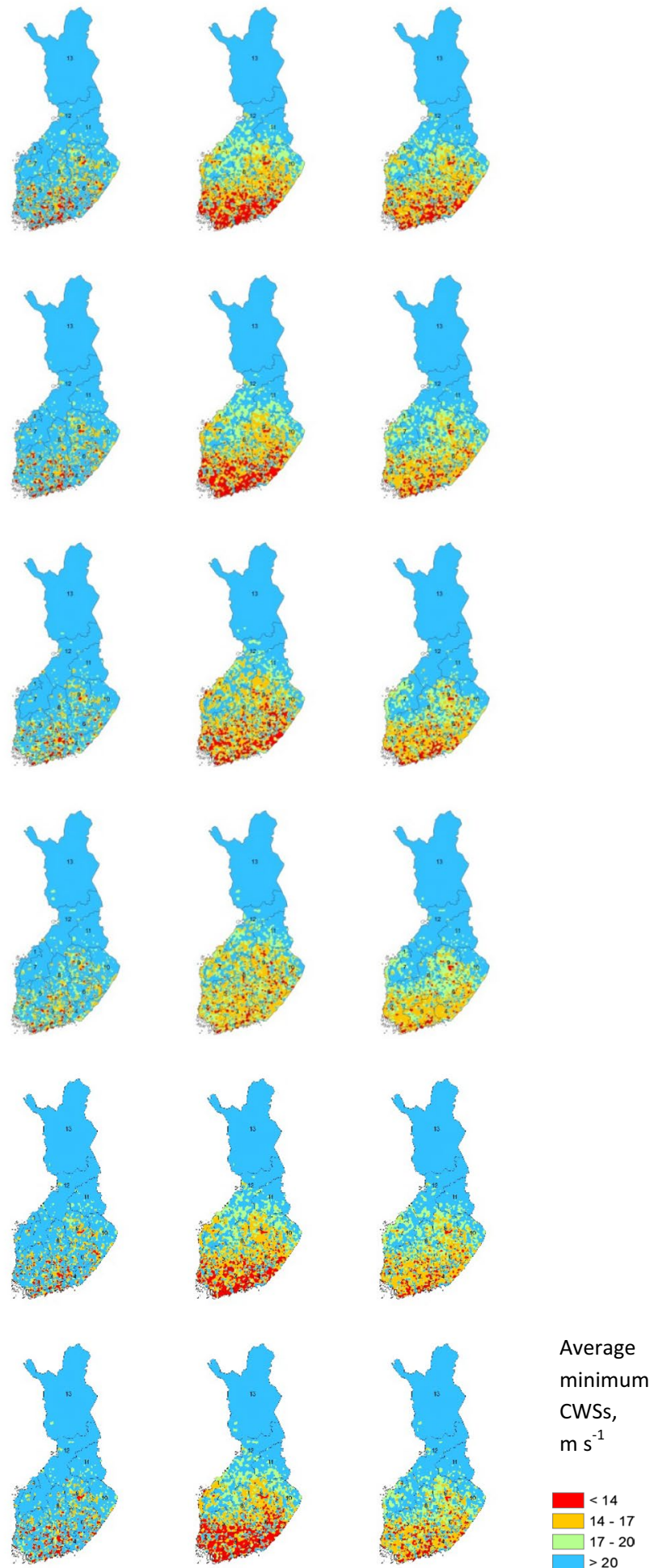

Average

CWSs,

$\mathrm{s} \mathrm{s}^{-1}$

Fig. 3 Average minimum CWSs $\left(\mathrm{m} \mathrm{s}^{-1}\right)$ in summer (birch in leaf) in the periods 2010-2039 and 2070-2099 under each climate change projection and management scenario. Red color indicates high wind damage risk. Medium-fertility sites were planted with Scots pine

(Pref. SP), Norway spruce (Pref. NS) or silver birch (Pref. B), or with the tree species that was dominant before the final clear-felling (baseline management). (Color figure online) 


$\begin{array}{llllll}\text { Autumn } & \text { 2010-2039 } & \text { 2070-2099 } & \text { 2070-2099 } & \text { 2070-2099 } & \text { 2070-2099 } \\ \text { (Birch leafless) } & \text { Baseline manag. } & \text { Baseline manag. } & \text { Pref. SP } & \text { Pref. NS } & \text { Pref. B }\end{array}$

Current climate
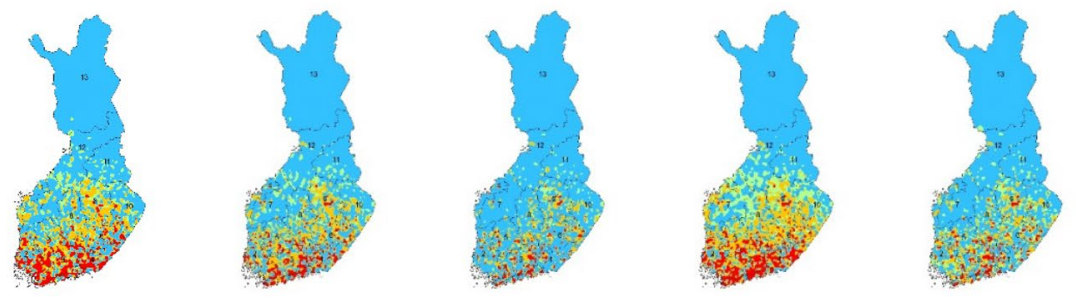

CNRM 8.5
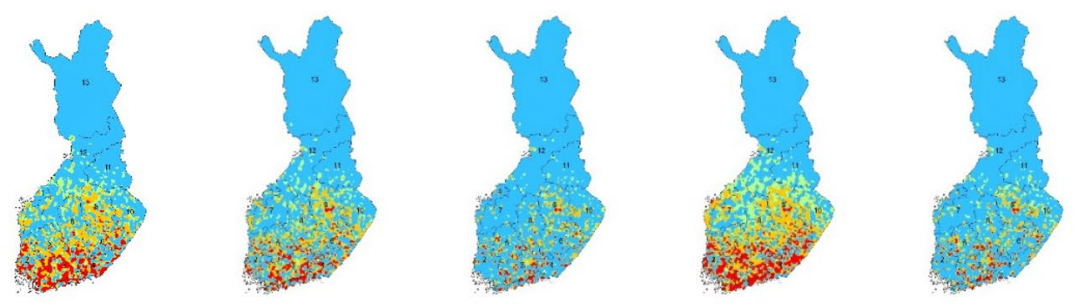

HadGEM2 8.5
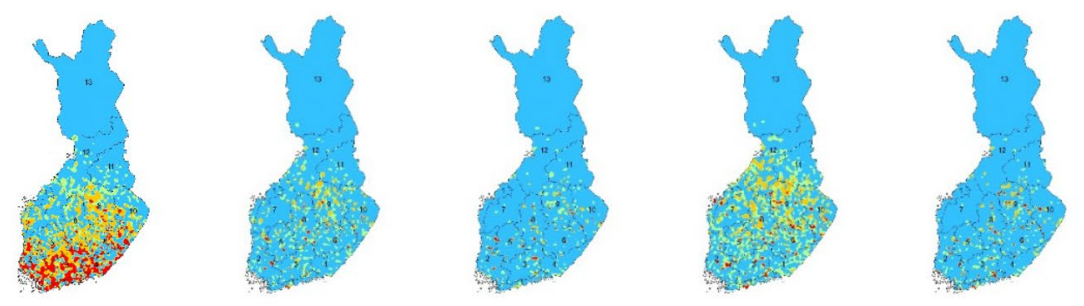

GFDL 8.5
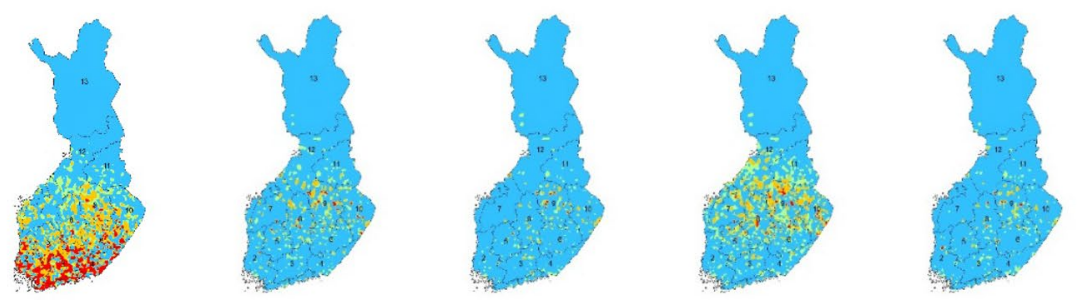

Mean RCP4.5
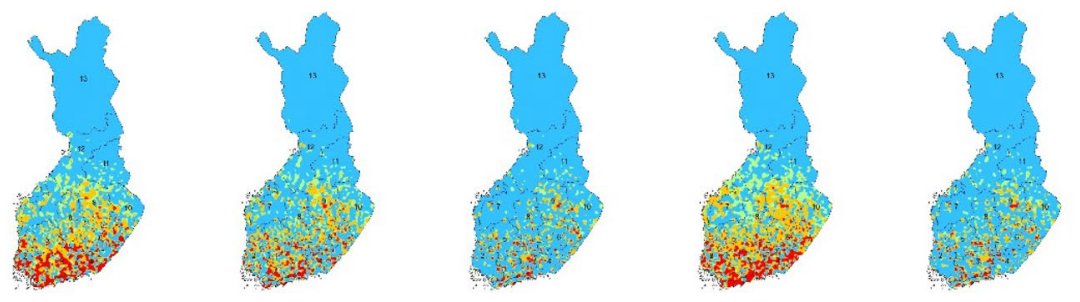

Mean RCP8.5
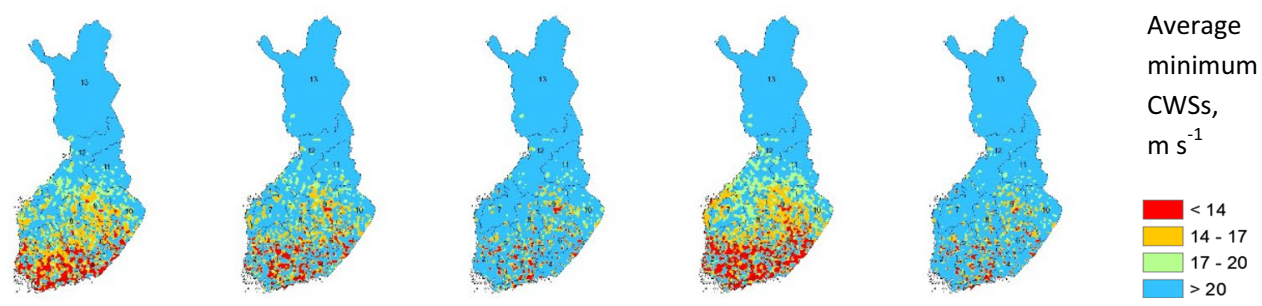

Fig. 4 Average minimum CWSs $\left(\mathrm{m} \mathrm{s}^{-1}\right)$ in autumn (birch leafless) in the periods 2010-2039 and 2070-2099 under each climate change projection and management scenario. Red color indicates high wind damage risk. Medium-fertility sites were planted with Scots pine
(Pref. SP), Norway spruce (Pref. NS) or silver birch (Pref. B), or with the tree species that was dominant before the final clear-felling (baseline management). (Color figure online) 


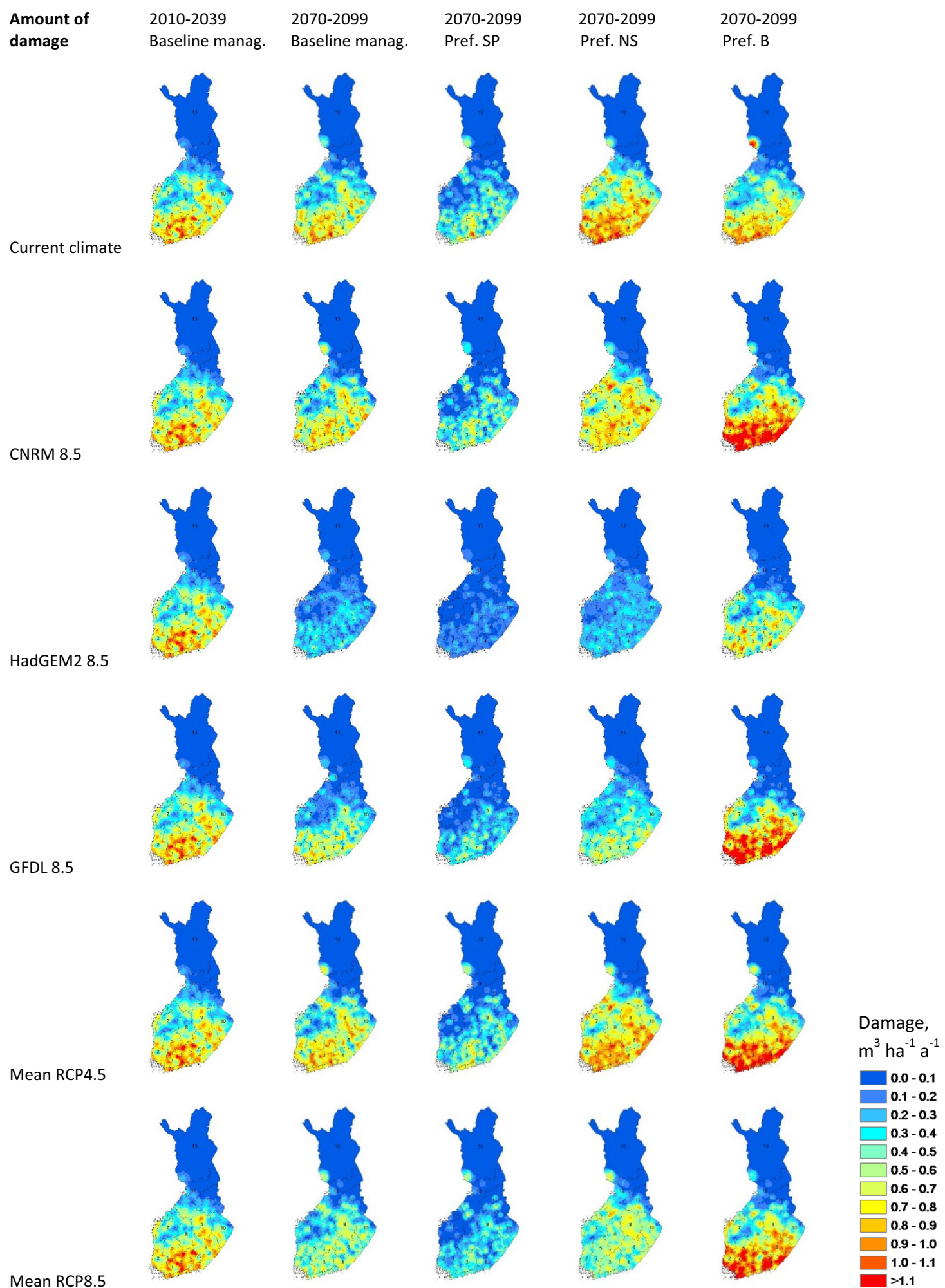

Fig. 5 Predicted amount of damage $\left(\mathrm{m}^{3} \mathrm{ha}^{-1} \mathrm{a}^{-1}\right)$ in summer in the periods 2010-2039 and 2070-2099 under each climate change projection and management scenario. Red color indicates high wind damage risk. Medium-fertility sites were planted with Scots pine
(Pref. SP), Norway spruce (Pref. NS) or silver birch (Pref. B), or with the tree species that was dominant before the final clear-felling (baseline management). (Color figure online) 
growing stock. Furthermore, the susceptibility to a certain disturbance is also affected by the forest structure (age, species) as controlled by forest management, and development phase of the forest.

On the other hand, we used outputs of the SIMA model simulations for 2010-2099 as inputs for HWIND, which predicted the CWSs needed to cause damage to various stand configurations. In addition, calculation of the risk of wind damage to the plots was done by always assuming new and vulnerable upwind edges, and considering only the most vulnerable tree cohort of a plot. As a result, we may have overestimated the predicted amount of wind damage to some degree. Furthermore, because damaged trees were not excluded from the stands during the SIMA model simulations, we may also have overestimated the forest growth in stands suffering damage, at least to some degree, over time. In future studies, damaged trees should be removed annually from the stands when simulating forest growth and dynamics over time.

The use of ecosystem modeling as combined with mechanistic wind damage modeling allowed us to study the effects of the growth responses of different tree species, forest dynamics and tree species preferences on the risk of wind damage under different climate projections. This would not be possible using statistical growth models alone, assuming no change in climate over time. The growth responses of the trees were also controlled in our simulations by water and nitrogen availability, which were affected by edaphic factors (climate and site). This allowed us to evaluate also how we should adapt the use of different tree species in forest regeneration in different regions, in order to better consider the uncertainties related to climate change and its projected impacts on forestry.

\section{Evaluation of main findings}

Based on our study, the use of individual GCMs, especially such as HadGEM2 8.5 and GFDL 8.5, affected more the development of a proportion of the tree species and the volume of growing stock (Fig. 1, Appendix Tables 6, 7), and thus the amount of damage (Fig. 2, Appendix Table 5), compared to the multi-model mean GCM projections (mean RCP4.5 and mean RCP8.5) used by Ikonen et al. (2017). Use of the most extreme GCM projections also affected the predicted amount of wind damage more than the increased use of different tree species in forest regeneration in the long term. When the GCMs with smaller changes in temperature and precipitation, such as
MPI 4.5 and MPI 8.5, were used, our results were similar to those of Ikonen et al. (2017).

Compared to the current climate, under CNRM 8.5 (significant increase in temperature, greatest increase in precipitation), with an increased use of birch in southern Finland, the predicted amount of wind damage (along with forest growth and volume of growing stock) increased markedly. On the other hand, under strong climate warming and decreased precipitation compared to the current climate, the growing conditions became unfavorable, especially for Norway spruce, as shown previously by Alrahahleh et al. (2018). Thus, especially under HadGEM2 8.5 in southern and central Finland, the volume of growing stock and the predicted amount of damage were remarkably low. In line with previous studies (e.g., Ikonen et al. 2017), the increased use of Scots pine in forest regeneration seemed to decrease the wind damage risks, as opposed to an increased use of Norway spruce. The trend of decreasing wind damage risk with increasing proportion of birch was, however, quite clear for autumn, when the birch was leafless. Norway spruce has been found the most vulnerable conifer to wind damage also in wind storms in both northern and central Europe (Schmidt et al. 2010; Reyer et al. 2017).

The growth (and mortality) responses of different tree species varied in regard to climate change severity, which greatly affected the proportions of tree species (of volume of growing stock) at the regional level as was reported by Alrahahleh et al. (2018). For example, with an increased use of Norway spruce, its proportion ranged from $1 \%$ (GFDL 8.5) to 64\% (MPI 4.5; Appendix Table 6). GFDL 8.5 predicted a very large increase in temperature, but only a moderate increase in precipitation in southern Finland, causing unfavorable conditions for Norway spruce. Contrarily, MPI 4.5 only produced a minor increase in temperature, but, as a result, the proportion of Norway spruce was the greatest under MPI 4.5, compared to the other climate change projections. Thus, the use of different tree species in forest regeneration will affect their proportions more under mild climate change than under severe climate change.

The most important factor for CWSs, and the probability of wind damage at the regional level, was in our study, the proportion of different tree species. At the tree and stand level, the wind damage risk and CWSs are largely affected by the different tree and stand characteristics and stand configurations (Peltola et al. 1999b; Zubizarreta-Gerendiain et al. 2012; Dupont et al. 2015; Suvanto et al. 2016). In 
our study, climate change directly affected the growth and mortality of the trees and, indirectly, the CWSs and the probability of damage, which in turn, together with the volume of the growing stock, affected the amount of wind damage.

Under Finnish conditions, relatively low wind speeds (i.e., CWSs $<17 \mathrm{~m} \mathrm{~s}^{-1}$ ) have caused wind damage in recent decades (Laiho 1987; Gregow et al. 2011a, 2011b; Zubizarreta-Gerendiain et al. 2012). Since 2000, about 1.6 million $\mathrm{m}^{3} \mathrm{a}^{-1}$ of timber has been damaged by windstorms, mostly in southern and central Finland (Laiho 1987; Gregow et al. 2011a; Zubizarreta-Gerendiain et al. 2012). By comparison, if we assume an annual regeneration area of about 1-2\% (Finnish Forest Research Institute 2014), and that each new upwind stand edge will be vulnerable about 20 years, according to our calculations, the total damaged amount of timber throughout Finland would be, on average, 0.5-2.4 and 0.9-2.6 million $\mathrm{m}^{3} \mathrm{a}^{-1}$ under different climate projections, with an increased planting of Scots pine and baseline management. In contrast, with an increased planting of Norway spruce or birch, the corresponding ranges would be higher, 1.0-3.0 and 1.9-3.0 million $\mathrm{m}^{3} \mathrm{a}^{-1}$, on average, respectively. The corresponding ranges calculated by Ikonen et al. (2017), based on the current climate and multi-model mean GCM projections, were of the same magnitude, but the ranges were narrower.

In the long term, the increasing risks to forests may, at least partly, counteract the expected increase in forest productivity under changing climate (Kellomäki et al. 2008; Reyer et al. 2017; Seidl et al. 2017). The higher share of Norway spruce might result in increased wind damage to forests (Schmidt et al. 2010; Reyer et al. 2017). It might cause also a greater risk of biotic damage (e.g., by wood decay and bark beetles; Subramanian et al. 2016; Thom and Seidl 2016; Honkaniemi et al. 2017), which were not considered in this study. Increasing abiotic and biotic damage risks to forests should be considered in adapting forest management strategies to properly accommodate/counteract projected climate change (Peltola et al. 2010; Seidl et al. 2011; Hanewinkel et al. 2013; Subramanian et al. 2016; Reyer et al. 2017). For example, growing forests with more climate change adapted tree species (genotypes), and their mixtures, could help to reduce the possible negative effects of climate change on forests (Neuner et al. 2015; Metz et al. 2016; Anyomi et al. 2017; Jactel et al. 2017). The wind damage risk to forests could also be lessened by avoiding the creation of large height differences among adjacent older stands and using shorter rotation lengths (Zeng et al. 2007; Heinonen et al. 2009; Jactel et al. 2009; ZubizarretaGerendiain et al. 2012).

\section{Conclusions}

The increasing use of certain tree species in forest regeneration may decrease the risk of wind damage in the long term, but the effect will depend on the current structure of the forests (age, tree species proportions), geographical region (climate and site) and the severity of the climate change, as well as the season and applied forest management intensity. Thus, opposite measures for risk management could be suggested, dependent on which climate change projection is used and the time span studied. In this sense, it is important to understand how different climate projections and management choices can affect the wind damage risk over the short and long term. This is crucial in order to identify the most appropriate and most flexible adaptation measures to climate change.

In future studies, different wood harvesting scenarios should be considered, as the intensity of wood harvesting can greatly affect the development of forest resources and, consequently, the wind damage risks. In addition, the effects of different abiotic and biotic damage risks to forests should be considered. More integrated models, with the capability of removing damaged trees from the forest during simulations, should be developed. All in all, the importance of considering the risks of various disturbances is increasing in forest management because such conditions can amplify, or even cancel out, any expected increases in forest productivity. Although our study represented a Finnish boreal case study, our findings could be applicable also to other regions especially in Northern Europe, but also partially in central Europe.

Acknowledgements Open access funding provided by University of Eastern Finland (UEF) including Kuopio University Hospital. This work was supported by the FORBIO (Sustainable, climate-neutral and resource-efficient forest-based bioeconomy) Project (Decision Number 314224), funded by the Strategic Research Council of the Academy of Finland, led by Prof. Heli Peltola at the University of Eastern Finland (2015-2021). The Natural Resources Institute Finland and the Finnish Meteorological Institute (Kimmo Ruosteenoja and Matti Kämäräinen) are acknowledged for, respectively, providing National Forest Inventory data and climatic data (for the current climate and changing climate).

Open Access This article is licensed under a Creative Commons Attribution 4.0 International License, which permits use, sharing, adaptation, distribution and reproduction in any medium or format, as long as you give appropriate credit to the original author(s) and the source, provide a link to the Creative Commons licence, and indicate if changes were made. The images or other third party material in this article are included in the article's Creative Commons licence, unless indicated otherwise in a credit line to the material. If material is not included in the article's Creative Commons licence and your intended use is not permitted by statutory regulation or exceeds the permitted use, you will need to obtain permission directly from the copyright holder. To view a copy of this licence, visit http://creativecommons.org/licenses/by/4.0/. 


\section{Appendix}

See Tables 3, 4, 5, 6 and 7.

Table 3 Average minimum critical wind speeds $\left(\mathrm{m} \mathrm{s}^{-1}\right)$ in summer (birch in leaf)

\begin{tabular}{llllllllllllll}
\hline 1 & 2 & 3 & 4 & 5 & 6 & 7 & 8 & 9 & 10 & 11 & 12 & 13 \\
$\mathrm{CU}$ & $\mathrm{H} 45$ & $\mathrm{H} 85$ & $\mathrm{M} 45$ & $\mathrm{M} 85$ & $\mathrm{Ca} 45$ & $\mathrm{Ca} 85$ & $\mathrm{Mi} 45$ & Mi85 & CN85 & GF85 & R45 & R85 \\
\hline
\end{tabular}

Southern Finland

2010-2039

$\begin{array}{cccccccccccccc}\text { Baseline } & 17 & 17 & 17 & 17 & 17 & 17 & 17 & 17 & 17 & 17 & 17 & 17 & 17 \\ \text { 2040-2069 } & & & & & & & & & & & & \\ \text { Baseline } & 18 & 18 & 18 & 18 & 18 & 18 & 18 & 18 & 18 & 18 & 18 & 18 & 18 \\ \text { Pref. SP } & 19 & 20 & 19 & 20 & 20 & 20 & 20 & 20 & 19 & 20 & 19 & 20 & 20 \\ \text { Pref. NS } & 17 & 17 & 17 & 17 & 17 & 17 & 17 & 17 & 17 & 17 & 16 & 17 & 17 \\ \text { Pref. B } & 17 & 18 & 17 & 17 & 18 & 17 & 17 & 17 & 18 & 18 & 17 & 17 & 18 \\ \text { 2070-2099 } & & & & & & & & & & & & & \\ \text { Baseline } & 18 & 18 & 18 & 18 & 18 & 18 & 18 & 19 & 18 & 18 & 18 & 18 & 18 \\ \text { Pref. SP } & 21 & 21 & 20 & 21 & 21 & 21 & 21 & 21 & 21 & 21 & 21 & 21 & 21 \\ \text { Pref. NS } & 16 & 16 & 16 & 17 & 17 & 17 & 16 & 17 & 16 & 16 & 17 & 17 & 16 \\ \text { Pref. B } & 17 & 18 & 17 & 17 & 17 & 18 & 17 & 18 & 17 & 17 & 18 & 17 & 17 \\ \text { Central Finland } & & & & & & & & & & & & \\ \text { 2010-2039a } & & & & & & & & & & & & \\ \text { Baseline } & 19 & 19 & 19 & 19 & 19 & 19 & 19 & 19 & 19 & 20 & 19 & 19 & 19 \\ \text { 2040-2069 } & & & & & & & & & & & & & \\ \text { Baseline } & 20 & 21 & 21 & 21 & 21 & 21 & 21 & 21 & 21 & 21 & 21 & 21 & 21 \\ \text { Pref. SP } & 21 & 22 & 22 & 22 & 22 & 22 & 22 & 22 & 22 & 22 & 22 & 22 & 22 \\ \text { Pref. NS } & 20 & 20 & 20 & 20 & 20 & 20 & 20 & 20 & 20 & 20 & 20 & 20 & 20 \\ \text { Pref. B } & 20 & 20 & 20 & 20 & 20 & 20 & 20 & 20 & 20 & 20 & 20 & 20 & 20 \\ \text { 2070-2099 } & & & & & & & & & & & & \\ \text { Baseline } & 21 & 21 & 21 & 21 & 21 & 21 & 21 & 21 & 21 & 21 & 21 & 21 & 21 \\ \text { Pref. SP } & 23 & 23 & 23 & 23 & 23 & 23 & 23 & 23 & 23 & 23 & 23 & 23 & 23 \\ \text { Pref. NS } & 19 & 19 & 19 & 19 & 19 & 19 & 18 & 19 & 19 & 19 & 19 & 19 & 19 \\ \text { Pref. B } & 20 & 20 & 20 & 20 & 20 & 20 & 20 & 20 & 20 & 20 & 20 & 20 & 20\end{array}$

Northern Finland

2010-2039

\begin{tabular}{cccccccccccccc} 
Baseline & 27 & 27 & 27 & 27 & 27 & 28 & 28 & 27 & 28 & 27 & 28 & 27 & 28 \\
2040-2069 & & & & & & & & & & & & \\
Baseline & 28 & 29 & 29 & 29 & 29 & 29 & 29 & 29 & 29 & 29 & 29 & 29 & 29 \\
Pref. SP & 28 & 29 & 29 & 29 & 29 & 29 & 29 & 29 & 29 & 29 & 29 & 29 & 29 \\
Pref. NS & 28 & 28 & 28 & 28 & 28 & 28 & 28 & 28 & 28 & 28 & 28 & 28 & 28 \\
Pref. B & 28 & 29 & 29 & 28 & 28 & 29 & 29 & 29 & 29 & 29 & 29 & 29 & 29 \\
2070-2099 & & & & & & & & & & & & \\
Baseline & 28 & 29 & 28 & 29 & 29 & 29 & 29 & 29 & 29 & 29 & 29 & 29 & 29 \\
Pref. SP & 29 & 30 & 29 & 30 & 30 & 30 & 30 & 30 & 30 & 30 & 30 & 30 & 30 \\
Pref. NS & 28 & 28 & 27 & 28 & 28 & 28 & 27 & 28 & 27 & 28 & 27 & 28 & 28 \\
Pref. B & 28 & 28 & 28 & 28 & 28 & 28 & 28 & 28 & 28 & 28 & 28 & 28 & 28 \\
\hline
\end{tabular}

Climate change projections: $\mathbf{1}=$ current climate, $\mathbf{2}=$ HadGEM2 $4.5, \mathbf{3}=$ HadGEM2 $8.5, \mathbf{4}=$ MPI 4.5 , $\mathbf{5}=$ MPI 8.5, $\mathbf{6}=$ CanESM2 4.5, 7=CanESM2 8.5, $8=$ MIROC5 4.5, $\mathbf{9}=$ MIROC5 8.5, 10=CNRM 8.5, $\mathbf{1 1}=$ GFDL 8.5, $\mathbf{1 2}=$ Mean RCP4.5, $13=$ Mean RCP8.5

${ }^{a}$ No remarkable differences between management scenarios in the first period 
Table 4 Probabilities for wind damage (dimensionless, in a range of $0-1)$

\begin{tabular}{|c|c|c|c|c|c|c|c|c|c|c|c|c|c|}
\hline & $\begin{array}{l}1 \\
\mathrm{CU}\end{array}$ & $\begin{array}{l}2 \\
\mathrm{H} 45\end{array}$ & $\begin{array}{l}3 \\
\text { H85 }\end{array}$ & $\begin{array}{l}4 \\
\text { M45 }\end{array}$ & $\begin{array}{l}5 \\
\text { M85 }\end{array}$ & $\begin{array}{l}6 \\
\mathrm{Ca} 45\end{array}$ & $\begin{array}{l}7 \\
\mathrm{Ca} 85\end{array}$ & $\begin{array}{l}8 \\
\text { Mi45 }\end{array}$ & $\begin{array}{l}9 \\
\text { Mi85 }\end{array}$ & $\begin{array}{l}10 \\
\mathrm{CN} 85\end{array}$ & $\begin{array}{l}11 \\
\text { GF85 }\end{array}$ & $\begin{array}{l}12 \\
\text { R45 }\end{array}$ & $\begin{array}{l}13 \\
\text { R85 }\end{array}$ \\
\hline \multicolumn{14}{|c|}{ Southern Finland } \\
\hline \multicolumn{14}{|l|}{$2010-2039^{a}$} \\
\hline Baseline & 0.8 & 0.8 & 0.8 & 0.8 & 0.8 & 0.8 & 0.8 & 0.8 & 0.8 & 0.8 & 0.8 & 0.8 & 0.8 \\
\hline \multicolumn{14}{|l|}{$2040-2069$} \\
\hline Baseline & 0.7 & 0.7 & 0.7 & 0.7 & 0.7 & 0.7 & 0.7 & 0.7 & 0.7 & 0.7 & 0.7 & 0.7 & 0.7 \\
\hline Pref. SP & 0.6 & 0.5 & 0.5 & 0.5 & 0.5 & 0.6 & 0.6 & 0.6 & 0.6 & 0.5 & 0.6 & 0.5 & 0.5 \\
\hline Pref. NS & 0.8 & 0.8 & 0.8 & 0.8 & 0.8 & 0.8 & 0.8 & 0.8 & 0.8 & 0.8 & 0.8 & 0.8 & 0.8 \\
\hline Pref. B & 0.8 & 0.8 & 0.8 & 0.8 & 0.8 & 0.8 & 0.8 & 0.8 & 0.8 & 0.8 & 0.8 & 0.8 & 0.8 \\
\hline \multicolumn{14}{|l|}{ 2070-2099 } \\
\hline Baseline & 0.7 & 0.6 & 0.7 & 0.6 & 0.6 & 0.6 & 0.7 & 0.6 & 0.7 & 0.6 & 0.7 & 0.6 & 0.6 \\
\hline Pref. SP & 0.4 & 0.4 & 0.4 & 0.4 & 0.4 & 0.4 & 0.4 & 0.4 & 0.4 & 0.4 & 0.4 & 0.4 & 0.4 \\
\hline Pref. NS & 0.8 & 0.8 & 0.8 & 0.8 & 0.8 & 0.8 & 0.8 & 0.8 & 0.8 & 0.8 & 0.8 & 0.8 & 0.8 \\
\hline Pref. B & 0.8 & 0.8 & 0.8 & 0.8 & 0.8 & 0.8 & 0.8 & 0.8 & 0.8 & 0.8 & 0.8 & 0.8 & 0.8 \\
\hline \multicolumn{14}{|c|}{ Central Finland } \\
\hline \multicolumn{14}{|l|}{$2010-2039^{a}$} \\
\hline Baseline & 0.6 & 0.6 & 0.6 & 0.6 & 0.6 & 0.6 & 0.6 & 0.6 & 0.6 & 0.6 & 0.6 & 0.6 & 0.6 \\
\hline \multicolumn{14}{|l|}{ 2040-2069 } \\
\hline Baseline & 0.5 & 0.5 & 0.5 & 0.5 & 0.5 & 0.5 & 0.5 & 0.5 & 0.5 & 0.5 & 0.5 & 0.5 & 0.5 \\
\hline Pref. SP & 0.4 & 0.4 & 0.4 & 0.4 & 0.4 & 0.4 & 0.4 & 0.4 & 0.4 & 0.4 & 0.4 & 0.4 & 0.4 \\
\hline Pref. NS & 0.6 & 0.6 & 0.6 & 0.6 & 0.6 & 0.6 & 0.6 & 0.6 & 0.6 & 0.6 & 0.6 & 0.6 & 0.6 \\
\hline Pref. B & 0.6 & 0.6 & 0.6 & 0.6 & 0.6 & 0.6 & 0.6 & 0.6 & 0.6 & 0.6 & 0.6 & 0.6 & 0.6 \\
\hline \multicolumn{14}{|l|}{ 2070-2099 } \\
\hline Baseline & 0.5 & 0.5 & 0.5 & 0.5 & 0.5 & 0.5 & 0.5 & 0.5 & 0.5 & 0.5 & 0.5 & 0.5 & 0.5 \\
\hline Pref. SP & 0.3 & 0.3 & 0.3 & 0.3 & 0.3 & 0.3 & 0.3 & 0.3 & 0.3 & 0.3 & 0.3 & 0.3 & 0.3 \\
\hline Pref. NS & 0.7 & 0.7 & 0.7 & 0.7 & 0.7 & 0.7 & 0.7 & 0.7 & 0.7 & 0.7 & 0.7 & 0.7 & 0.7 \\
\hline Pref. B & 0.6 & 0.6 & 0.5 & 0.6 & 0.6 & 0.6 & 0.5 & 0.6 & 0.5 & 0.6 & 0.5 & 0.6 & 0.6 \\
\hline \multicolumn{14}{|c|}{ Northern Finland } \\
\hline \multicolumn{14}{|l|}{$2010-2039^{a}$} \\
\hline Baseline & 0.1 & 0.1 & 0.1 & 0.1 & 0.1 & 0.1 & 0.1 & 0.1 & 0.1 & 0.1 & 0.1 & 0.1 & 0.1 \\
\hline \multicolumn{14}{|l|}{ 2040-2069 } \\
\hline Baseline & 0.1 & 0.1 & 0.1 & 0.1 & 0.1 & 0.1 & 0.1 & 0.1 & 0.1 & 0.1 & 0.1 & 0.1 & 0.1 \\
\hline Pref. SP & 0.1 & 0.0 & 0.0 & 0.0 & 0.0 & 0.0 & 0.0 & 0.0 & 0.0 & 0.0 & 0.0 & 0.0 & 0.0 \\
\hline Pref. NS & 0.1 & 0.1 & 0.1 & 0.1 & 0.1 & 0.1 & 0.1 & 0.1 & 0.1 & 0.1 & 0.1 & 0.1 & 0.1 \\
\hline Pref. B & 0.1 & 0.1 & 0.1 & 0.1 & 0.1 & 0.1 & 0.1 & 0.1 & 0.1 & 0.1 & 0.1 & 0.1 & 0.1 \\
\hline \multicolumn{14}{|l|}{ 2070-2099 } \\
\hline Baseline & 0.1 & 0.1 & 0.1 & 0.1 & 0.1 & 0.1 & 0.1 & 0.1 & 0.1 & 0.1 & 0.1 & 0.1 & 0.1 \\
\hline Pref. SP & 0.0 & 0.0 & 0.0 & 0.0 & 0.0 & 0.0 & 0.0 & 0.0 & 0.0 & 0.0 & 0.0 & 0.0 & 0.0 \\
\hline Pref. NS & 0.1 & 0.1 & 0.1 & 0.1 & 0.1 & 0.1 & 0.1 & 0.1 & 0.1 & 0.1 & 0.1 & 0.1 & 0.1 \\
\hline Pref. B & 0.1 & 0.1 & 0.0 & 0.1 & 0.1 & 0.1 & 0.0 & 0.1 & 0.1 & 0.1 & 0.0 & 0.1 & 0.1 \\
\hline
\end{tabular}

Climate change projections: $\mathbf{1}=$ current climate, $\mathbf{2}=$ HadGEM2 $4.5, \mathbf{3}=$ HadGEM2 $8.5, \mathbf{4}=$ MPI 4.5 , $\mathbf{5}=$ MPI 8.5, $\mathbf{6}=$ CanESM2 4.5, 7=CanESM2 8.5, $8=$ MIROC5 4.5, $\mathbf{9}=$ MIROC5 8.5, 10=CNRM 8.5, $\mathbf{1 1}=$ GFDL 8.5, $\mathbf{1 2}=$ Mean RCP4.5, $\mathbf{1 3}=$ Mean RCP8.5

${ }^{a}$ No remarkable differences between management scenarios in the first period 
Table 5 Predicted amount of damage $\left(\mathrm{m}^{3} \mathrm{ha}^{-1} \mathrm{a}^{-1}\right)$

\begin{tabular}{|c|c|c|c|c|c|c|c|c|c|c|c|c|c|}
\hline & $\begin{array}{l}1 \\
\mathrm{CU}\end{array}$ & $\begin{array}{l}2 \\
\mathrm{H} 45\end{array}$ & $\begin{array}{l}3 \\
\text { H85 }\end{array}$ & $\begin{array}{l}4 \\
\text { M45 }\end{array}$ & $\begin{array}{l}5 \\
\text { M85 }\end{array}$ & $\begin{array}{l}6 \\
\mathrm{Ca} 45\end{array}$ & $\begin{array}{l}7 \\
\mathrm{Ca} 85\end{array}$ & $\begin{array}{l}8 \\
\text { Mi45 }\end{array}$ & $\begin{array}{l}9 \\
\text { Mi85 }\end{array}$ & $\begin{array}{l}10 \\
\text { CN85 }\end{array}$ & $\begin{array}{l}11 \\
\text { GF85 }\end{array}$ & $\begin{array}{l}12 \\
\text { R45 }\end{array}$ & $\begin{array}{l}13 \\
\text { R85 }\end{array}$ \\
\hline \multicolumn{14}{|c|}{ Southern Finland } \\
\hline \multicolumn{14}{|l|}{$2010-2039^{\mathrm{a}}$} \\
\hline Baseline & 0.7 & 0.7 & 0.7 & 0.7 & 0.7 & 0.7 & 0.7 & 0.7 & 0.7 & 0.7 & 0.7 & 0.7 & 0.7 \\
\hline \multicolumn{14}{|l|}{ 2040-2069 } \\
\hline Baseline & 0.5 & 0.5 & 0.5 & 0.6 & 0.6 & 0.6 & 0.5 & 0.5 & 0.5 & 0.6 & 0.5 & 0.6 & 0.6 \\
\hline Pref. SP & 0.4 & 0.4 & 0.4 & 0.5 & 0.4 & 0.5 & 0.4 & 0.5 & 0.4 & 0.5 & 0.4 & 0.5 & 0.4 \\
\hline Pref. NS & 0.6 & 0.5 & 0.5 & 0.6 & 0.6 & 0.6 & 0.5 & 0.6 & 0.5 & 0.6 & 0.5 & 0.6 & 0.6 \\
\hline Pref. B & 0.6 & 0.7 & 0.7 & 0.7 & 0.7 & 0.8 & 0.7 & 0.8 & 0.8 & 0.8 & 0.8 & 0.7 & 0.8 \\
\hline \multicolumn{14}{|l|}{ 2070-2099 } \\
\hline Baseline & 0.6 & 0.6 & 0.3 & 0.7 & 0.6 & 0.6 & 0.4 & 0.6 & 0.5 & 0.6 & 0.5 & 0.6 & 0.5 \\
\hline Pref. SP & 0.4 & 0.3 & 0.1 & 0.4 & 0.4 & 0.4 & 0.2 & 0.4 & 0.3 & 0.4 & 0.3 & 0.4 & 0.3 \\
\hline Pref. NS & 0.8 & 0.6 & 0.2 & 0.8 & 0.8 & 0.7 & 0.3 & 0.7 & 0.4 & 0.7 & 0.5 & 0.8 & 0.5 \\
\hline Pref. B & 0.7 & 0.9 & 0.6 & 0.8 & 0.9 & 0.9 & 0.8 & 0.9 & 0.9 & 1.0 & 0.9 & 0.9 & 0.9 \\
\hline \multicolumn{14}{|c|}{ Central Finland } \\
\hline \multicolumn{14}{|l|}{$2010-2039^{\mathrm{a}}$} \\
\hline Baseline & 0.5 & 0.5 & 0.5 & 0.5 & 0.5 & 0.5 & 0.5 & 0.5 & 0.5 & 0.5 & 0.5 & 0.5 & 0.5 \\
\hline \multicolumn{14}{|l|}{ 2040-2069 } \\
\hline Baseline & 0.4 & 0.4 & 0.3 & 0.4 & 0.4 & 0.4 & 0.4 & 0.4 & 0.4 & 0.4 & 0.4 & 0.4 & 0.4 \\
\hline Pref. SP & 0.3 & 0.3 & 0.3 & 0.3 & 0.3 & 0.3 & 0.3 & 0.3 & 0.3 & 0.3 & 0.3 & 0.3 & 0.3 \\
\hline Pref. NS & 0.4 & 0.4 & 0.4 & 0.4 & 0.4 & 0.4 & 0.4 & 0.4 & 0.4 & 0.5 & 0.4 & 0.4 & 0.4 \\
\hline Pref. B & 0.4 & 0.4 & 0.4 & 0.4 & 0.4 & 0.5 & 0.4 & 0.5 & 0.4 & 0.5 & 0.5 & 0.5 & 0.5 \\
\hline \multicolumn{14}{|l|}{ 2070-2099 } \\
\hline Baseline & 0.4 & 0.4 & 0.2 & 0.5 & 0.5 & 0.4 & 0.3 & 0.4 & 0.3 & 0.5 & 0.3 & 0.5 & 0.4 \\
\hline Pref. SP & 0.3 & 0.2 & 0.1 & 0.3 & 0.3 & 0.3 & 0.1 & 0.3 & 0.2 & 0.3 & 0.2 & 0.3 & 0.2 \\
\hline Pref. NS & 0.6 & 0.5 & 0.2 & 0.6 & 0.7 & 0.6 & 0.3 & 0.6 & 0.3 & 0.6 & 0.3 & 0.6 & 0.5 \\
\hline Pref. B & 0.4 & 0.5 & 0.4 & 0.5 & 0.5 & 0.5 & 0.5 & 0.5 & 0.5 & 0.6 & 0.5 & 0.5 & 0.5 \\
\hline \multicolumn{14}{|c|}{ Northern Finland } \\
\hline \multicolumn{14}{|l|}{$2010-2039^{a}$} \\
\hline Baseline & 0.1 & 0.1 & 0.1 & 0.1 & 0.1 & 0.1 & 0.1 & 0.1 & 0.1 & 0.1 & 0.1 & 0.1 & 0.1 \\
\hline \multicolumn{14}{|l|}{ 2040-2069 } \\
\hline Baseline & 0.1 & 0.1 & 0.1 & 0.1 & 0.1 & 0.1 & 0.1 & 0.1 & 0.1 & 0.1 & 0.1 & 0.1 & 0.1 \\
\hline Pref. SP & 0.1 & 0.1 & 0.1 & 0.1 & 0.1 & 0.1 & 0.1 & 0.1 & 0.1 & 0.1 & 0.1 & 0.1 & 0.1 \\
\hline Pref. NS & 0.1 & 0.1 & 0.1 & 0.1 & 0.1 & 0.1 & 0.1 & 0.1 & 0.1 & 0.1 & 0.1 & 0.1 & 0.1 \\
\hline Pref. B & 0.1 & 0.1 & 0.1 & 0.1 & 0.1 & 0.1 & 0.1 & 0.1 & 0.1 & 0.1 & 0.1 & 0.1 & 0.1 \\
\hline \multicolumn{14}{|l|}{ 2070-2099 } \\
\hline Baseline & 0.1 & 0.1 & 0.0 & 0.1 & 0.1 & 0.1 & 0.1 & 0.1 & 0.1 & 0.1 & 0.0 & 0.1 & 0.1 \\
\hline Pref. SP & 0.1 & 0.1 & 0.0 & 0.1 & 0.1 & 0.1 & 0.0 & 0.1 & 0.0 & 0.1 & 0.0 & 0.1 & 0.1 \\
\hline Pref. NS & 0.1 & 0.1 & 0.1 & 0.1 & 0.1 & 0.1 & 0.1 & 0.1 & 0.1 & 0.1 & 0.1 & 0.1 & 0.1 \\
\hline Pref. B & 0.1 & 0.1 & 0.0 & 0.1 & 0.1 & 0.1 & 0.0 & 0.1 & 0.1 & 0.1 & 0.0 & 0.1 & 0.1 \\
\hline
\end{tabular}

Climate change projections: $\mathbf{1}=$ current climate, $\mathbf{2}=$ HadGEM2 $4.5, \mathbf{3}=$ HadGEM2 $8.5, \mathbf{4}=$ MPI 4.5 , $\mathbf{5}=$ MPI 8.5, $\mathbf{6}=$ CanESM2 4.5, 7=CanESM2 8.5, $8=$ MIROC5 4.5, $\mathbf{9}=$ MIROC5 8.5, 10=CNRM 8.5, $\mathbf{1 1}=$ GFDL 8.5, $\mathbf{1 2}=$ Mean RCP4.5, $\mathbf{1 3}=$ Mean RCP8.5

${ }^{a}$ No remarkable differences between management scenarios in the first period 
Table 6 The proportion of each tree species (percentage of stem volume, \%) under each climate change projection in the first period 2010-2039 (P1) under baseline management and in the third period 2070-2099 (P3) under each management scenario
Climate change projection

\begin{tabular}{lllllllllllll}
\hline 1 & 2 & 3 & 4 & 5 & 6 & 7 & 8 & 9 & 10 & 11 & 12 & 13 \\
$\mathrm{CU}$ & $\mathrm{H} 45$ & $\mathrm{H} 85$ & $\mathrm{M} 45$ & $\mathrm{M} 85$ & $\mathrm{Ca} 45$ & $\mathrm{Ca} 85$ & Mi45 & Mi85 & CN85 & GF85 & R45 & R85
\end{tabular}

\begin{tabular}{|c|c|c|c|c|c|c|c|c|c|c|c|c|c|}
\hline \multicolumn{14}{|l|}{ Scots pine } \\
\hline \multicolumn{14}{|l|}{ Baseline } \\
\hline \multicolumn{14}{|l|}{$\mathrm{P} 1$} \\
\hline North & 65 & 65 & 65 & 65 & 65 & 65 & 65 & 65 & 65 & 65 & 65 & 65 & 65 \\
\hline Central & 51 & 51 & 51 & 51 & 51 & 51 & 51 & 51 & 51 & 51 & 51 & 51 & 51 \\
\hline South & 42 & 42 & 42 & 42 & 42 & 42 & 42 & 42 & 42 & 42 & 42 & 42 & 42 \\
\hline \multicolumn{14}{|l|}{ Baseline } \\
\hline \multicolumn{14}{|l|}{ P3 } \\
\hline North & 62 & 69 & 75 & 67 & 68 & 70 & 75 & 70 & 73 & 69 & 75 & 68 & 70 \\
\hline Central & 52 & 62 & 74 & 59 & 61 & 61 & 72 & 61 & 71 & 61 & 69 & 60 & 64 \\
\hline South & 48 & 56 & 62 & 52 & 54 & 54 & 63 & 55 & 59 & 56 & 54 & 53 & 61 \\
\hline \multicolumn{14}{|l|}{ Pref. SP } \\
\hline \multicolumn{14}{|l|}{ P3 } \\
\hline North & 75 & 80 & 85 & 78 & 79 & 79 & 84 & 79 & 83 & 79 & 84 & 79 & 80 \\
\hline Central & 73 & 79 & 89 & 77 & 79 & 78 & 87 & 79 & 85 & 78 & 83 & 78 & 81 \\
\hline South & 72 & 78 & 87 & 75 & 77 & 76 & 85 & 76 & 81 & 77 & 77 & 75 & 81 \\
\hline \multicolumn{14}{|l|}{ Pref. NS } \\
\hline \multicolumn{14}{|l|}{$\mathrm{P} 3$} \\
\hline North & 47 & 52 & 57 & 50 & 51 & 53 & 58 & 53 & 56 & 52 & 59 & 51 & 53 \\
\hline Central & 33 & 39 & 52 & 36 & 38 & 39 & 53 & 40 & 52 & 39 & 52 & 37 & 41 \\
\hline South & 27 & 34 & 40 & 29 & 30 & 32 & 42 & 33 & 41 & 34 & 41 & 30 & 40 \\
\hline \multicolumn{14}{|l|}{ Pref. B } \\
\hline \multicolumn{14}{|l|}{ P3 } \\
\hline North & 52 & 61 & 62 & 57 & 59 & 62 & 63 & 62 & 64 & 61 & 63 & 59 & 62 \\
\hline Central & 41 & 42 & 31 & 50 & 51 & 44 & 36 & 43 & 36 & 47 & 34 & 48 & 44 \\
\hline South & 38 & 28 & 20 & 40 & 37 & 29 & 22 & 28 & 22 & 34 & 20 & 34 & 30 \\
\hline \multicolumn{14}{|c|}{ Norway spruce } \\
\hline \multicolumn{14}{|l|}{ Baseline } \\
\hline \multicolumn{14}{|l|}{$\mathrm{P} 1$} \\
\hline North & 22 & 21 & 22 & 22 & 22 & 21 & 21 & 21 & 21 & 22 & 21 & 21 & 22 \\
\hline Central & 31 & 30 & 30 & 31 & 31 & 30 & 30 & 30 & 30 & 31 & 30 & 31 & 31 \\
\hline South & 40 & 38 & 38 & 39 & 39 & 38 & 38 & 38 & 38 & 39 & 37 & 39 & 38 \\
\hline \multicolumn{14}{|l|}{ Baseline } \\
\hline \multicolumn{14}{|l|}{ P3 } \\
\hline North & 29 & 24 & 19 & 26 & 25 & 24 & 19 & 23 & 20 & 24 & 17 & 25 & 23 \\
\hline Central & 39 & 29 & 6 & 36 & 34 & 30 & 8 & 30 & 10 & 32 & 5 & 34 & 27 \\
\hline South & 43 & 22 & 1 & 39 & 35 & 27 & 2 & 24 & 3 & 29 & 1 & 35 & 18 \\
\hline \multicolumn{14}{|l|}{ Pref. SP } \\
\hline \multicolumn{14}{|l|}{ P3 } \\
\hline North & 20 & 16 & 11 & 17 & 17 & 16 & 12 & 16 & 13 & 17 & 11 & 17 & 16 \\
\hline Central & 22 & 14 & 2 & 19 & 18 & 16 & 3 & 15 & 5 & 17 & 2 & 18 & 13 \\
\hline South & 23 & 9 & 1 & 19 & 16 & 13 & 1 & 11 & 1 & 14 & 1 & 17 & 7 \\
\hline \multicolumn{14}{|l|}{ Pref. NS } \\
\hline P3 & & & & & & & & & & & & & \\
\hline North & 47 & 43 & 38 & 46 & 45 & 43 & 38 & 43 & 39 & 43 & 35 & 44 & 43 \\
\hline Central & 62 & 53 & 15 & 60 & 57 & 54 & 20 & 52 & 24 & 55 & 10 & 57 & 50 \\
\hline South & 67 & 44 & 3 & 64 & 61 & 52 & 6 & 47 & 7 & 53 & 1 & 61 & 38 \\
\hline
\end{tabular}


Table 6 (continued)

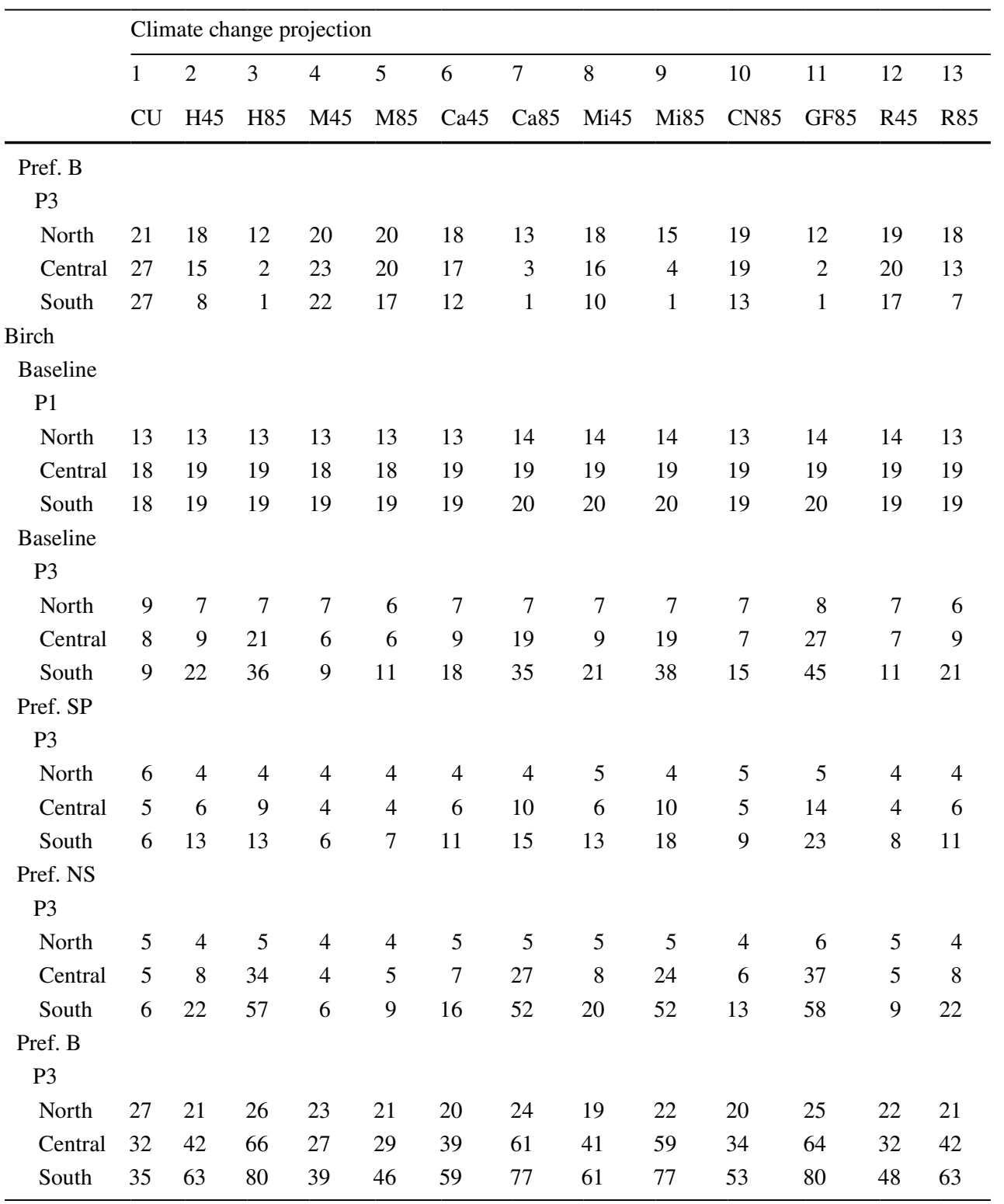

$\mathbf{1}=$ current climate, $\mathbf{2}=$ HadGEM2 4.5, $\mathbf{3}=$ HadGEM2 8.5, $\mathbf{4}=$ MPI 4.5, $\mathbf{5}=$ MPI $8.5, \mathbf{6}=$ CanESM2 4.5 , $\mathbf{7}=$ CanESM2 $8.5, \mathbf{8}=$ MIROC5 4.5, 9=MIROC5 8.5, 10=CNRM 8.5, 11=GFDL 8.5, $12=$ Mean RCP4.5, $13=$ Mean RCP8.5 
Table 7 Average volume of growing stock $\left(\mathrm{m}^{3} \mathrm{ha}^{-1}\right)$

\begin{tabular}{|c|c|c|c|c|c|c|c|c|c|c|c|c|c|}
\hline & $\begin{array}{l}1 \\
\mathrm{CU}\end{array}$ & $\begin{array}{l}2 \\
\mathrm{H} 45\end{array}$ & $\begin{array}{l}3 \\
\text { H85 }\end{array}$ & $\begin{array}{l}4 \\
\text { M45 }\end{array}$ & $\begin{array}{l}5 \\
\text { M85 }\end{array}$ & $\begin{array}{l}6 \\
\mathrm{Ca} 45\end{array}$ & $\begin{array}{l}7 \\
\mathrm{Ca} 85\end{array}$ & $\begin{array}{l}8 \\
\text { Mi45 }\end{array}$ & $\begin{array}{l}9 \\
\text { Mi85 }\end{array}$ & $\begin{array}{l}10 \\
\text { CN85 }\end{array}$ & $\begin{array}{l}11 \\
\text { GF85 }\end{array}$ & $\begin{array}{l}12 \\
\text { R45 }\end{array}$ & $\begin{array}{l}13 \\
\text { R85 }\end{array}$ \\
\hline \multicolumn{14}{|c|}{ Southern Finland } \\
\hline \multicolumn{14}{|l|}{$2010-2039^{a}$} \\
\hline Baseline & 129 & 132 & 132 & 133 & 133 & 133 & 133 & 132 & 132 & 133 & 133 & 133 & 134 \\
\hline \multicolumn{14}{|l|}{ 2040-2069 } \\
\hline Baseline & 109 & 111 & 101 & 120 & 121 & 117 & 109 & 115 & 110 & 123 & 108 & 119 & 119 \\
\hline Pref. SP & 116 & 118 & 108 & 125 & 124 & 122 & 115 & 122 & 115 & 129 & 113 & 126 & 124 \\
\hline Pref. NS & 110 & 100 & 86 & 113 & 112 & 105 & 95 & 104 & 94 & 115 & 91 & 110 & 108 \\
\hline Pref. B & 114 & 123 & 119 & 123 & 125 & 129 & 126 & 129 & 127 & 133 & 129 & 128 & 130 \\
\hline \multicolumn{14}{|l|}{ 2070-2099 } \\
\hline Baseline & 140 & 126 & 64 & 152 & 147 & 140 & 86 & 138 & 101 & 144 & 107 & 148 & 119 \\
\hline Pref. SP & 145 & 134 & 71 & 152 & 150 & 144 & 97 & 143 & 109 & 150 & 108 & 150 & 130 \\
\hline Pref. NS & 146 & 109 & 44 & 151 & 142 & 127 & 61 & 123 & 73 & 130 & 80 & 143 & 95 \\
\hline Pref. B & 128 & 142 & 89 & 140 & 146 & 151 & 117 & 152 & 132 & 157 & 139 & 149 & 141 \\
\hline \multicolumn{14}{|c|}{ Central Finland } \\
\hline \multicolumn{14}{|c|}{$2010-2039^{\mathrm{a}}$} \\
\hline Baseline & 122 & 125 & 126 & 125 & 126 & 126 & 127 & 126 & 126 & 127 & 128 & 126 & 126 \\
\hline \multicolumn{14}{|l|}{ 2040-2069 } \\
\hline Baseline & 107 & 115 & 108 & 118 & 120 & 119 & 114 & 117 & 114 & 123 & 112 & 120 & 120 \\
\hline Pref. SP & 113 & 119 & 114 & 122 & 123 & 123 & 120 & 122 & 119 & 127 & 119 & 123 & 126 \\
\hline Pref. NS & 108 & 107 & 98 & 114 & 114 & 111 & 103 & 110 & 104 & 117 & 100 & 114 & 113 \\
\hline Pref. B & 110 & 118 & 116 & 118 & 119 & 122 & 121 & 124 & 122 & 125 & 124 & 121 & 123 \\
\hline \multicolumn{14}{|l|}{ 2070-2099 } \\
\hline Baseline & 129 & 139 & 78 & 148 & 151 & 146 & 96 & 147 & 106 & 154 & 108 & 149 & 136 \\
\hline Pref. SP & 134 & 141 & 90 & 148 & 151 & 147 & 108 & 148 & 117 & 155 & 117 & 150 & 142 \\
\hline Pref. NS & 134 & 132 & 54 & 148 & 149 & 142 & 71 & 141 & 83 & 150 & 84 & 146 & 126 \\
\hline Pref. B & 118 & 136 & 98 & 129 & 136 & 141 & 116 & 141 & 126 & 146 & 130 & 135 & 137 \\
\hline \multicolumn{14}{|c|}{ Northern Finland } \\
\hline \multicolumn{14}{|c|}{$2010-2039^{a}$} \\
\hline Baseline & 94 & 100 & 101 & 99 & 99 & 102 & 102 & 102 & 102 & 100 & 103 & 100 & 101 \\
\hline \multicolumn{14}{|l|}{ 2040-2069 } \\
\hline Baseline & 102 & 130 & 133 & 124 & 128 & 134 & 136 & 134 & 137 & 134 & 140 & 129 & 135 \\
\hline Pref. SP & 104 & 130 & 135 & 123 & 127 & 134 & 138 & 135 & 138 & 135 & 141 & 130 & 136 \\
\hline Pref. NS & 104 & 124 & 127 & 120 & 124 & 129 & 130 & 129 & 131 & 129 & 133 & 125 & 130 \\
\hline Pref. B & 101 & 124 & 129 & 117 & 121 & 128 & 132 & 128 & 132 & 129 & 137 & 123 & 129 \\
\hline \multicolumn{14}{|l|}{ 2070-2099 } \\
\hline Baseline & 126 & 168 & 142 & 161 & 173 & 174 & 153 & 172 & 162 & 181 & 161 & 169 & 175 \\
\hline Pref. SP & 128 & 169 & 144 & 161 & 172 & 172 & 155 & 173 & 161 & 180 & 163 & 170 & 176 \\
\hline Pref. NS & 130 & 166 & 133 & 161 & 171 & 172 & 146 & 173 & 157 & 179 & 153 & 168 & 173 \\
\hline Pref. B & 120 & 154 & 135 & 148 & 157 & 158 & 147 & 158 & 153 & 167 & 155 & 155 & 161 \\
\hline
\end{tabular}

Climate change projections: $\mathbf{1}=$ current climate, $\mathbf{2}=$ HadGEM2 $4.5, \mathbf{3}=$ HadGEM2 8.5, $\mathbf{4}=$ MPI 4.5, $\mathbf{5}=$ MPI 8.5, $\mathbf{6}=$ CanESM2 4.5, $\mathbf{7}=$ CanESM2 8.5, $8=$ MIROC5 4.5, $\mathbf{9}=$ MIROC5 8.5, 10=CNRM 8.5, $\mathbf{1 1}=$ GFDL 8.5, $\mathbf{1 2}=$ Mean RCP4.5, $\mathbf{1 3}=$ Mean RCP8.5

${ }^{a}$ No remarkable differences between management scenarios in the first period

\section{References}

Aalto J, Pirinen P, Heikkinen J, Venäläinen A (2013) Spatial interpolation of monthly climate data for Finland: comparing the performance of kriging and generalized additive models. Theor
Appl Climatol 112(1-2):99-111. https://doi.org/10.1007/s0070 4-012-0716-9

Aalto J, Pirinen P, Jylhä K (2016) New gridded daily climatology of Finland: Permutation-based uncertainty estimates and temporal trends in climate. J Geophys Res Atmos 121:3807-3823. https:// doi.org/10.1002/2015JD024651 
Äijälä O, Koistinen A, Sved J, Vanhatalo K, Väisänen P (eds) (2014) Hyvän metsänhoidon suositukset-Metsänhoito (Recommendations for good forest management—-forest management). Forestry Development Centre, Tapio (in Finnish)

Alrahahleh L, Ikonen V-P, Kilpeläinen A, Torssonen P, Strandman H, Asikainen A, Kaurola J, Venäläinen A, Peltola H (2017) Effects of forest conservation and management on volume growth, harvested amount of timber, carbon stock and amount of deadwood in Finnish boreal forests under changing climate. Can J For Res 47(2):215-225. https://doi.org/10.1139/cjfr-2016-0153

Alrahahleh L, Kilpeläinen A, Ikonen V-P, Strandman H, Asikainen A, Venäläinen A, Kaurola J, Kangas J, Peltola H (2018) Effects of using certain tree species in forest regeneration on volume growth, timber yield, and carbon stock of boreal forests in Finland under different CMIP5 projections. Eur J For Res 137(5):573-591. https://doi.org/10.1007/s10342-018-1126-z

Ancelin P, Courbaud B, Fourcaud T (2004) Development of an individual tree-based mechanical model to predict wind damage within forest stands. Forest Ecol Manag 203:101-121. https:// doi.org/10.1016/j.foreco.2004.07.067

Anyomi KA, Mitchell SJ, Perera AH, Ruel J-C (2017) Windthrow dynamics in Boreal Ontario: a simulation of the vulnerability of several stand types across a range of wind speeds. Forest 8:233. https://doi.org/10.3390/f8070233

Bergh J, Freeman M, Sigurdsson B, Kellomäki S, Laitinen K, Niinistö S, Peltola H, Linder S (2003) Modelling the shortterm effects of climate change on the productivity of selected tree species in Nordic countries. For Ecol Manag 183:327-340. https://doi.org/10.1016/S0378-1127(03)00117-8

Blennow K, Sallnäs O (2004) WINDA-a system of models for assessing the probability of wind damage to forest stands within a landscape. Ecol Model 175:87-99. https://doi.org/10.1016/j. ecolmodel.2003.10.009

Briceño-Elizondo E, Garcia-Gonzalo J, Peltola H, Matala J, Kellomäki S (2006) Sensitivity of growth of Scots pine, Norway spruce and silver birch to climate change and forest management in boreal conditions. For Ecol Manag 232(1-3):152-167. https ://doi.org/10.1016/j.foreco.2006.05.062

Bugmann H, Fischlin A, Kienast F (1996) Model convergence and state variable update in forest gap models. Ecol Model 89:197-208

Dupont S, Ikonen V-P, Väisänen H, Peltola H (2015) Predicting tree damage in fragmented landscapes using a wind risk model coupled with an airflow model. Can J For Res 45:1065-1076. https:// doi.org/10.1139/cjfr-2015-0066

Finnish Forest Research Institute (2014) Statistical yearbook of forestry 2014. Finnish Forest Research Institute, Helsinki, Finland. Vammalan Kirjapaino, Sastamala

Garcia-Gonzalo J, Peltola H, Zubizarreta-Gerendiain A, Kellomäki S (2007) Impacts of forest landscape structure and management on timber production and carbon stocks in the boreal forest ecosystem under changing climate. For Ecol Manag 241(1-3):243-257. https://doi.org/10.1016/j.foreco.2007.01.008

Gardiner B, Blennow K, Carnus J-M, Fleischer P, Ingemarson F, Landmann G, Lindner M, Marzano M, Nicoll B, Orazio C et al. (2010) Destructive storms in European forests: past and forthcoming impacts. Final report to European Commission-DG Environment. European Forestry Institute, Joensuu, Finland

Gardiner BA, Byrne K, Hale S, Kamimura K, Mitchell SJ, Peltola $\mathrm{H}$, Ruel JC (2008) A review of mechanistic modelling of wind damage risk to forests. Forestry 81(3):447-463. https://doi. org/10.1093/forestry/cpn022

Gardiner BA, Peltola H, Kellomäki S (2000) Comparison of two models for predicting the critical wind speeds required to damage coniferous trees. Ecol Model 129:1-23
Gregow H, Peltola H, Laapas M, Saku S, Venäläinen A (2011a) Combined occurrence of wind, snow loading and soil frost with implications for risks to forestry in Finland under the current and changing climatic conditions. Silva Fenn 45(1):35-54. https://doi. org/10.14214/sf.30

Gregow H, Ruosteenoja K, Pimenoff N, Jylhä K (2011b) Changes in the mean and extreme geostrophic wind speeds in northern Europe until 2100 based on nine global climate models. Int J Climatol 32:1834-1846. https://doi.org/10.1002/joc.2398

Hanewinkel M, Cullmann DA, Schelhaas M-J, Nabuurs G-J, Zimmermann NE (2013) Climate change may cause severe loss in the economic value of European forest land. Nat Clim Change 3:203-207. https://doi.org/10.1038/nclimate1687

Heinonen T, Pukkala T, Ikonen V-P, Peltola H, Venäläinen A, Dupont S (2009) Integrating the risk of wind damage into forest planning. For Ecol Manag 258(7):1567-1577. https://doi.org/10.1016/j. foreco.2009.07.006

Honkaniemi J, Lehtonen M, Väisänen H, Peltola H (2017) Effects of wood decay by Heterobasidion annosum on the vulnerability of Norway spruce stands to wind damage: a mechanistic modelling approach. Can J For Res 47(6):777-787. https://doi.org/10.1139/ cjfr-2016-0505

Hynynen J, Ojansuu R, Hökkä H, Siipilehto J, Salminen H, Haapala $P$ (2002) Models for predicting stand development in the MELA system. Finnish Forest Research Institute, Research Paper 835

Ikonen V-P, Kilpeläinen A, Zubizarreta-Gerendiain A, Strandman H, Asikainen A, Venäläinen A, Kaurola J, Kangas J, Peltola H (2017) Regional risks of wind damage in boreal forests under changing management and climate projections. Can J For Res 47(12):16321645. https://doi.org/10.1139/cjfr-2017-0183

Jactel H, Bauhus J, Boberg J, Bonal D, Castagneyrol B, Gardiner B, Gonzalez-Olabarria JR, Koricheva J, Meurisse N, Brockerhoff EG (2017) Tree diversity drives forest stand resistance to natural disturbances. Curr For Rep 3(3):223-243. https://doi.org/10.1007/ s40725-017-0064-1

Jactel H, Nicoll BC, Branco M, Gonzalez-Olabarria JR, Grodzki W, Långström B, Moreira F, Netherer S, Orazio C, Piou D, Santos H (2009) The influences of forest stand management on biotic and abiotic risks of damage. Ann For Sci 66(7):701-701. https://doi. org/10.1051/forest/2009054

Jyske T, Hölttä T, Mäkinen H, Nöjd P, Lumme I, Spiecker H (2010) The effect of artificially induced drought on radial increment and wood properties of Norway spruce. Tree Physiol 30(1):103-115. https://doi.org/10.1093/treephys/tpp099

Järvinen O, Vänni T (1994) Sadeveden pitoisuus- ja laskeuma-arvot Suomessa vuonna 1993. Ministry of water and environment mimeograph 579 (in Finnish)

Kellomäki S, Maajärvi M, Strandman H, Kilpeläinen A, Peltola $\mathrm{H}$ (2010) Model computations of the climate change effects on snow cover, soil moisture and soil frost in the boreal conditions over Finland. Silva Fenn 44(2):213-233

Kellomäki S, Peltola H, Nuutinen T, Korhonen KT, Strandman H (2008) Sensitivity of managed boreal forests in Finland to climate change, with implications for adaptive management. Philos Trans R Soc B Biol Sci 363:2341-2351. https://doi.org/10.1098/ rstb.2007.2204

Kellomäki S, Strandman H, Heinonen T, Asikainen A, Venäläinen A, Peltola H (2018) Temporal and spatial change in diameter growth of Boreal Scots Pine, Norway spruce, and birch under recentgeneration (CMIP5) global climate model projections for the $21 \mathrm{st}$ century. Forests 9:118. https://doi.org/10.3390/f9030118

Kellomäki S, Strandman H, Nuutinen T, Peltola H, Korhonen KT, Väisänen H (2005) Adaptation of forest ecosystems, forests and forestry to climate change. FINADAPT. Working Paper 4. Finnish Environment Institute Mimeographs 334, Helsinki 
Kienast F (1987) FORECE: a forest succession model for southern central Europe. Oak Ridge National Laboratory, Oak Ridge, TN Environmental Science Division. Publication No. 2989:1-73

Koca D, Smith B, Sykes MT (2006) Modelling regional climate change effects on potential natural ecosystems in Sweden. Clim Change 78:381-406. https://doi.org/10.1007/s10584-005-9030-1

Korhonen KT (2016) National forest inventories: assessment of wood availability and use: Finland. In: Vidal C, Alberdi I, Hernandez L, Redmond JJ (eds) National forest inventories: assessment of wood availability and use. Springer, Berlin, pp 369-384

Laiho O (1987) Metsiköiden alttius tuulituhoille Etelä-Suomessa (Susceptibility of forest stands to wind throw in Southern Finland). Folia For 706:1-24 (in Finnish with English summary)

Lehtonen I, Kämäräinen M, Gregow H, Venäläinen A, Peltola H (2016a) Heavy snow loads in Finnish forests respond regionally asymmetrically to projected climate change. Nat Hazards Earth Syst Sci 16:2259-2271. https://doi.org/10.5194/nhess -16-2259-2016

Lehtonen I, Venäläinen A, Kämäräinen M, Asikainen A, Laitila J, Anttila P, Peltola H (2018) Projected decrease in wintertime bearing capacity on different forest and soil types in Finland under a warming climate. Hydrol Earth Syst Sci. https://doi.org/10.5194/ hess-2017-727

Lehtonen I, Venäläinen A, Kämäräinen M, Peltola H, Gregow H (2016b) Risk of large-scale fires in boreal forests of Finland under changing climate. Nat Hazards Earth Syst Sci 16:239-253. https ://doi.org/10.5194/nhess-16-239-2016

Lindner M, Maroschek M, Netherer S, Kremer A, Barbati A, GarciaGonzalo J, Seidl R, Delzon S, Corona P, Kolström M, Lexer MJ, Marchetti M (2010) Climate change impacts, adaptive capacity, and vulnerability of European forest ecosystems. For Ecol Manag 259(4):698-709. https://doi.org/10.1016/j.foreco.2009.09.023

Metz J, Annighöfer P, Schall P, Zimmermann J, Kahl T, Schulze E-D, Ammer C (2016) Site-adapted admixed tree species reduce drought susceptibility of mature European beech. Glob Change Biol 22:903-920. https://doi.org/10.1111/gcb.13113

Mölter T, Schindler D, Albrecht AT, Kohnle U (2016) Review on the projections of future storminess over the North Atlantic European region. Atmosphere 7(4):60. https://doi.org/10.3390/atmos70400 60

Neuner S, Albrecht A, Cullmann D, Engels F, Griess VC, Hahn WA, Hanewinkel M, Härtl F, Kölling C, Staupendahl K, Knoke T (2015) Survival of Norway spruce remains higher in mixed stands under a dryer and warmer climate. Glob Change Biol 21:935-946. https://doi.org/10.1111/gcb.12751

Nikolov N, Helmisaari H (1992) Silvics of the circumpolar forests tree species. In: Shugart HH, Leemans R, Bonan GB (eds) A system analysis of the global boreal forest. Cambridge University Press, New York, pp 13-84

Nikulin G, Kjellström E, Hansson U, Strandberg G, Ullerstig A (2011) Evaluation and projections of temperature, precipitation and wind extremes over Europe in an ensemble of regional climate simulations. Tellus A 63:41-55. https://doi.org/10.111 1/j.1600-0870.2010.00466.x

Outten S, Esau I (2013) Extreme winds over Europe in the ENSAMBLES regional climate models. Atmos Chem Phys 13:5163-5172. https://doi.org/10.5194/acp-13-5163-2013

Peltola H, Ikonen V-P, Gregow H, Strandman H, Kilpeläinen A, Venäläinen A, Kellomäki S (2010) Impacts of climate change on timber production and regional risks of wind-induced damage to forests in Finland. For Ecol Manag 260(5):833-845. https://doi. org/10.1016/j.foreco.2010.06.001

Peltola H, Kellomäki S, Hassinen A, Granander M (2000) Mechanical stability of Scots pine, Norway spruce and birch: an analysis of tree-pulling experiments in Finland. For Ecol Manag 135(13):143-153. https://doi.org/10.1016/S0378-1127(00)00306-6
Peltola H, Kellomäki S, Väisänen H (1999a) Model computations of the impact of climatic change on the windthrow risk of trees. Clim Change 41:17-36. https://doi.org/10.1023/A:1005399822319

Peltola H, Kellomäki S, Väisänen H, Ikonen V-P (1999b) A mechanistic model for assessing the risk of wind and snow damage to single trees and stands of Scots pine, Norway spruce and birch. Can J For Res 29:647-661. https://doi.org/10.1139/x99-029

Poudel BC, Sathre R, Gustavsson L, Bergh J, Lundström A, Hyvönen $R$ (2011) Effects of climate change on biomass production and substitution in north-central Sweden. Biomass Bioenerg 35:4340 4355. https://doi.org/10.1016/j.biombioe.2011.08.005

Pryor S, Barthelmie R, Clausen N, Drews M, MacKellar N, Kjellström E (2012) Analyses of possible changes in intense and extreme wind speeds over northern Europe under climate change scenarios. Clim Dyn 38:189-208. https://doi.org/10.1007/s0038 2-010-0955-3

Räisänen J, Räty O (2013) Projections of daily mean temperature variability in the future: cross-validation tests with ENSEMBLES regional climate models. Clim Dyn 41:1553-1568. https://doi. org/10.1007/s00382-012-1515-9

Räty O, Räisänen J, Ylhäisi JS (2014) Evaluation of delta change and bias correction methods for future daily precipitation: intermodal cross-validation using ENSEMBLES simulations. Clim Dyn 42:2287-2303. https://doi.org/10.1007/s00382-014-2130-8

Reyer C, Bathgate S, Blennow K, Borges JG, Bugmann H, Delzon S, Faias SP, Garcia-Gonzalo J, Gardiner B, Gonzalez-Olabarria JR, Gracia C, Hernández JG, Kellomäki S, Kramer K, Lexer MJ, Lindner M, van der Maaten E, Maroschek M, Muys B, Nicoll B, Palahi M, Palma JHN, Paulo JA, Peltola H, Pukkala T, Rammer W, Ray D, Sabaté S, Schelhaas M-J, Seidl R, Temperli C, Tomé M, Yousefpour R, Zimmermann NE, Hanewinkel M (2017) Are forest disturbances amplifying or cancelling out climate changeinduced productivity changes in European forests? Environ Res Lett 12(3):034027. https://doi.org/10.1088/1748-9326/aa5ef1

Routa J, Kellomäki S, Kilpeläinen A, Peltola H, Strandman H (2011) Effects of forest management on the carbon dioxide emissions of wood energy in integrated production of timber and energy biomass. GCB Bioenergy 3:483-497. https://doi.org/10.111 1/j.1757-1707.2011.01106.x

Ruosteenoja K, Jylhä K, Kämäräinen M (2016) Climate projections for Finland under the RCP forcing scenarios. Geophysica 51(1):17-50

Ruosteenoja K, Markkanen T, Venäläinen A, Räisänen P, Peltola H (2018) Seasonal soil moisture and drought occurrence in Europe in CMIP5 projections for the 21st century. Clim Dynam 50(34):1177-1192. https://doi.org/10.1007/s00382-017-3671-4

Schelhaas M-J, Nabuurs GJ, Schuck A (2003) Natural disturbances in the European forests in the 19th and 20th centuries. Glob Change Biol 9:1620-1633. https://doi.org/10.104 6/j.1365-2486.2003.00684.x

Schmidt M, Hanewinkel M, Kändler G, Kublin E, Kohnle U (2010) An inventory-based approach for modeling single-tree storm damage-experiences with the winter storm of 1999 in southwestern Germany. Can J For Res 40(8):1636-1652. https://doi. org/10.1139/X10-099

Schuck A, Schelhaas M-J (2013) Storm damage in Europe - An overview. In: Gardiner B, Schuck A, Schelhaas M-J, Orazio C, Blennow K, Nicoll B (eds), Living with Storm Damage to Forests. What Science Can Tell Us 3. European Forestry Institute, Joensuu, Finland, pp. 15-23

Seidl R, Lexer MJ (2013) Forest management under climatic and social uncertainty: trade-offs between reducing climate change impacts and fostering adaptive capacity. J Environ Manag 114:461-469. https://doi.org/10.1016/j.jenvman.2012.09.028

Seidl R, Rammer W, Blennow K (2014) Simulating wind disturbance impacts on forest landscapes: tree-level heterogeneity matters. 
Environ Modell Softw 51:1-11. https://doi.org/10.1016/j.envso ft.2013.09.018

Seidl R, Schelhaas M-J, Lexer MJ (2011) Unraveling the drivers of intensifying forest disturbance regimes in Europe. Glob Change Biol 17:2842-2852. https://doi.org/10.111 1/j.1365-2486.2011.02452.x

Seidl R, Thom D, Kautz M, Martin-Benito D, Peltoniemi M, Vacchiano G, Wild J, Ascoli D, Petr M, Honkaniemi J, Lexer MJ, Trotsiuk V, Mairota P, Svoboda M, Fabrika M, Nagel TA, Reyer CPO (2017) Forest disturbances under climate change. Nat Clim Change 7(6):395-402. https://doi.org/10.1038/nclimate3303

Subramanian N, Bergh J, Johansson U, Nilsson U, Sallnäs O (2016) Adaptation of forest management regimes in southern Sweden to increased risks associated with climate change. Forests 7(1):8. https://doi.org/10.3390/f7010008

Suvanto S, Henttonen HM, Nöjd P, Mäkinen H (2016) Forest susceptibility to storm damage is affected by similar factors regardless of storm type: comparison of thunder storms and autumn extratropical cyclones in Finland. For Ecol Manag 381:17-28. https:// doi.org/10.1016/j.foreco.2016.09.005

Talkkari A, Peltola H, Kellomäki S, Strandman H (2000) Integration of component models from tree, stand and regional levels to assess the risk of wind damage at forest margins. Wind and other abiotic risks to forests. For Ecol Manag Special Issue 135(1-3):303313. https://doi.org/10.1016/S0378-1127(00)00288-7

Thom D, Seidl R (2016) Natural disturbance impacts on ecosystem services and biodiversity in temperate and boreal forests. Biol Rev 91:760-781. https://doi.org/10.1111/brv.12193

Torssonen P, Strandman H, Kellomäki S, Kilpeläinen A, Jylhä K, Asikainen A, Peltola H (2015) Do we need to adapt the choice of main boreal tree species in forest regeneration under the projected climate change? Forestry 88(5):564-572. https://doi.org/10.1093/ forestry/cpv023

Venäläinen A, Tuomenvirta H, Pirinen P, Drebs A (2005) A basic Finnish climate dataset 1961-2000 - Descriptions and illustrations. Meteorological Report No. 2005:5. Finnish Meteorological Institute, Helsinki

Zeng H, Peltola H, Talkkari A, Strandman H, Venäläinen A, Wang K, Kellomäki S (2006) Simulations of the influence of clear-cutting on the risk of wind damage on a regional scale over a 20-year period. Can J For Res 36:2247-2258. https://doi.org/10.1139/ x06-123

Zeng H, Pukkala T, Peltola H (2007) The use of heuristic optimization in risk management of wind damage in forest planning. For Ecol Manag 241:189-199. https://doi.org/10.1016/j.foreco.2007.01.016

Zubizarreta-Gerendiain A, Pellikka P, Garcia-Gonzalo J, Ikonen V-P, Peltola H (2012) Factors affecting wind and snow damage of individual trees in a small management unit in Finland assessment based on inventoried damage and mechanistic modelling. Silva Fenn 46(2):181-196. https://doi.org/10.14214/sf.441

Zubizarreta-Gerendiain A, Pukkala T, Peltola H (2017) Effects of wind damage on the optimal management of boreal forests under current and changing climatic conditions. Can J For Res 47(2):246256. https://doi.org/10.1139/cjfr-2016-0226

Publisher's Note Springer Nature remains neutral with regard to jurisdictional claims in published maps and institutional affiliations. 